Research Article

\title{
Study on Roof Breakage-Induced Roadway Coal Burst in an Extrathick Steeply Inclined Coal Seam
}

\author{
Sheng-chuan Wang $\mathbb{D}^{1,2}$ Lin-ming Dou $\mathbb{D}^{1,},{ }^{1,2}$ Zong-long $\mathrm{Mu}^{2}{ }^{2}$ Jin-rong Cao, ${ }^{1,2}$ \\ and Xu-wei Li $\mathbb{I D}^{2}$ \\ ${ }^{1}$ Key Laboratory of Deep Coal Resource Mining, Ministry of Education of China, Xuzhou, China \\ ${ }^{2}$ School of Mines, China University of Mining and Technology, Xuzhou 221116, China \\ Correspondence should be addressed to Lin-ming Dou; lmdou@126.com
}

Received 26 July 2019; Accepted 17 September 2019; Published 30 October 2019

Academic Editor: Chengzhi Shi

Copyright ( 92019 Sheng-chuan Wang et al. This is an open access article distributed under the Creative Commons Attribution License, which permits unrestricted use, distribution, and reproduction in any medium, provided the original work is properly cited.

\begin{abstract}
In view of the coal burst induced by roof breakage in the steeply inclined coal seam (SICS) roadway and its mechanism, a mechanical model was established to investigate the distribution of dynamic and static stresses in the coal seam before and after the breakage of a thick hard roof. The aim of this research is to study failure laws of SICS roadways under the superposition of dynamic load induced by roof breakage and asymmetric static load. For this purpose, response characteristics including acoustic emission (AE), static stress, and acceleration were analyzed by applying different dynamic loads to different horizontal slices with a self-made similarity simulation test apparatus under combined dynamic and static loads. The theoretical model and simulation results were verified by analyzing characteristics of coal burst occurrence in the field, microseismic (MS) events, and tomographic imaging of microseismic waves. The study demonstrates the following: (1) The abutment pressure of the roof plays a dominant role in stress distribution of the coal seam slice before the breakage of the thick hard roof with the stress of the roof roadway $\left(R_{\mathrm{r}}\right)$ being obviously higher than that of the floor roadway $\left(R_{\mathrm{f}}\right)$. (2) High-energy MS events and AE events are concentrated on the roof side after the breakage of the thick hard roof, and coal bursts are more easily induced by the superposition of high dynamic and static stresses on the roof side. Coal burst in the roadway is jointly determined by dynamic and static stresses. Under the same static stress, response characteristics increase with the rise of intensity of dynamic loads. When dynamic stress is the same, coal burst easily occurs in the roadway with high static stress.
\end{abstract}

\section{Introduction}

According to statistics, steeply inclined coal seams (SICSs) are being mined in more than 100 mines in more than 20 key mining areas in China. The SICS is widely distributed in many coal-producing areas in China, such as Xinjiang Uygur Autonomous Region, Gansu Province, Ningxia Hui Autonomous Region, and Guizhou Province [1-4], with coal output accounting for about $5 \%$ of the total. In recent years, with the constant increase of depth and intensity of coal mining, mining-induced strata behavior is becoming increasingly intense in horizontal slices of extrathick steeply inclined coal seams, and many coal burst accidents even occurred $[5,6]$. As a typical dynamic disaster in coal mines, coal burst refers to the sudden failure of coal and rock mass in the mining space and the release of a large amount of energy, producing forces that throw coal and rock into the free space, which seriously threatens the safety of personnel and property in coal mines [7-10]. On July 2, 2013, a coal burst accident happened in the B3 6 working face of Wudong Coal Mine in Xinjiang Uygur Autonomous Region, resulting in roadway floor heaving of $200 \sim 450 \mathrm{~mm}$ within $100 \mathrm{~m}$ ahead of the working face. On May 31, 2005, a coal burst accident took place in the tunneling face of the 603 roof roadway in Huating Coal Mine in Gansu Province, resulting in one dead and 12 injured people.

Scholars in the world have studied the forms of roof breakage and stress distribution of coal and rock for SICSs through many means, such as theoretical analysis, 
similarity simulation test, numerical simulation, and field observation. As for theoretical analysis, Wu [11] established a fractured inclined masonry roof structure for SICS mining and pointed out that unbalanced displacement is the dominant cause of buckling failure of supports in the stope. Zhang and Shi [12] built an arch structure of multiple strata for SICS mining. When the frictional resistance on the contact surface between coal masses fails to resist the arch shear force and there are less top coal and residual waste rock, sliding and structural instability would occur, respectively, thus inducing weighting. In terms of the laboratory test, based on the similarity simulation test and field observations, Shao [13] built up the theory of "Large and Small Structures" of the overlying structural stratus body and found that failure of surrounding rocks mainly developed toward the top coal and roof. With the caving of top coal, failure developed upward and roof may form an arch. Wu et al. [14] proposed the inclined masonry structure of dip direction and antidip direction pile types and pointed out that the unbalanced movement of these structures was the primary factor in the instability of the "R-S-F" system. In the aspect of the coal burst mechanism of steeply inclined coal seams, $\mathrm{Li}$ and $\mathrm{Ju}[15]$ constructed a fracturing model of main roof strata of the cantilever beam structure for SICS slicing mining and deduced the expression of elastic energy of the main roof of the cantilever beam structure. Lai et al. $[16,17]$ established a stress model of the roof for SICS mining based on the beam theory and revealed the deformation law. Furthermore, they carried out a laboratory test and found that rock pillar fracturing underwent elastic deformation, microfracturing, and fracturing-induced instability in sequence. In this process, the radiation zone temperature decreased gradually, while the AE energy rate increased continuously.

Previous theoretical, experimental, and simulation studies on the extrathick SICS were mainly focused on breakage modes of overlying strata and the corresponding mechanical structure formed after breakage, while how dynamic and static stresses before and after roof breakage affect stress distribution in the working faces and roadways was rarely studied. In the meanwhile, the existing studies were mostly focused on the normal ground pressure in the SICS stope, while there were few researches on the SICS roadway coal burst. Moreover, the influence of released dynamic energy due to roof breakage was ignored, which cannot accurately reflect the dynamic deformation and failure process of roadways under superposed dynamic and static loads. For this reason, this study established a theoretical model, conducted the similarity simulation test under combined dynamic and static loads, and performed on-site MS monitoring. On this basis, static stress distribution in the extrathick SICS working face before roof breakage and the mechanism of the roof breakage-induced coal burst in the roof roadway were investigated.

\section{Distribution Characteristics of Dynamic and Static Stresses in the Extrathick Steeply Inclined Coal Seam}

2.1. Distribution Characteristics of Static Stress of Coal and Rock in the Panel. Under the influences of the occurrence structure, stresses on the roof and floor sides of the working face in the same horizontal slice are quite different in the SICS. For a specific slice, they are mainly affected by selfweight, abutment pressures $\sigma_{\mathrm{r}}$ and $\sigma_{\mathrm{f}}$ on the roof and floor sides, pressure $P_{\mathrm{r}}$ of overlying rock mass scattered in the gob, and abutment pressure $P_{\mathrm{f}}$ of coal mass on the bottom. The mechanical model was built, as shown in Figure 1. The coal mass is divided into a triangle coal zone on the roof (I), a rectangular coal zone (II), and a triangle coal zone on the floor, respectively.

Abutment pressure of bottom coal is determined by stress of the roof and floor and scattered overlying rock blocks. As scattered overlying rock blocks are in a stable state for a certain period of time, they slightly change stress of the working face. As demonstrated in Figure 1(b), stress of the OC side shows lateral stress distribution of the working face. In the figure, the xoy Cartesian coordinate system is established along the horizontal and vertical directions with the vertex of the slice at the lower left corner as the origin, where, $L, h, \mathrm{AE}$, and $\theta$, respectively, represent the length (m) of the slice, the height $(\mathrm{m})$ of the slice, the boundary of the triangular zone on the roof, and the dip angle $\left({ }^{\circ}\right)$ of the coal seam.

Stress in the triangular zone on the roof is shown in Figure 1(c). To simplify the calculation, it is considered that the AE boundary is subjected to uniformly distributed stress $\sigma_{x 1}$, while the OA side bears nonuniformly distributed abutment pressure $\sigma_{\mathrm{r}}$ of the roof. Moreover, $F_{\mathrm{r} 1}$ and $G_{1}$ represent the frictional force between the roof and coal mass and gravity of the triangular zone on the roof, respectively.

$$
G_{1}=\gamma_{c} h^{2} \cot \theta
$$

where $\gamma_{\mathrm{c}}$ indicates the average volume force $\left(\mathrm{kN} / \mathrm{m}^{3}\right)$ of coal mass and generally has a value of $14 \mathrm{kN} / \mathrm{m}^{3}$.

Based on the stress model in Figure 1(c), the static equilibrium equation of the triangular zone on the roof is shown as follows:

$$
\left\{\begin{array}{l}
\int_{0}^{h / \sin \theta} \sigma_{\mathrm{r}} \cos \theta \mathrm{d} l_{\mathrm{OA}}-\int_{0}^{h / \sin \theta} \sigma_{\mathrm{r}} \cdot f \cos \theta \mathrm{d} l_{\mathrm{OA}}-\sigma_{x 1} \cdot h=0, \\
\int_{0}^{h \cot \theta} P_{f 1} \mathrm{~d} x-\int_{0}^{h / \sin \theta} \sigma_{\mathrm{r}} \sin \theta \mathrm{d} l_{\mathrm{OA}}-\int_{0}^{h / \sin \theta} \sigma_{\mathrm{r}} \\
\quad f \sin \theta \mathrm{d} l_{\mathrm{OA}}-G_{1}=0
\end{array}\right.
$$

where $f$ and $P_{\mathrm{f} 1}$ indicate the frictional coefficient between roof and coal mass and the abutment stress of the bottom in the range of $\mathrm{OE}$, respectively. The stress distribution equation [12] of $\sigma_{\mathrm{r}}$ is presented as follows: 


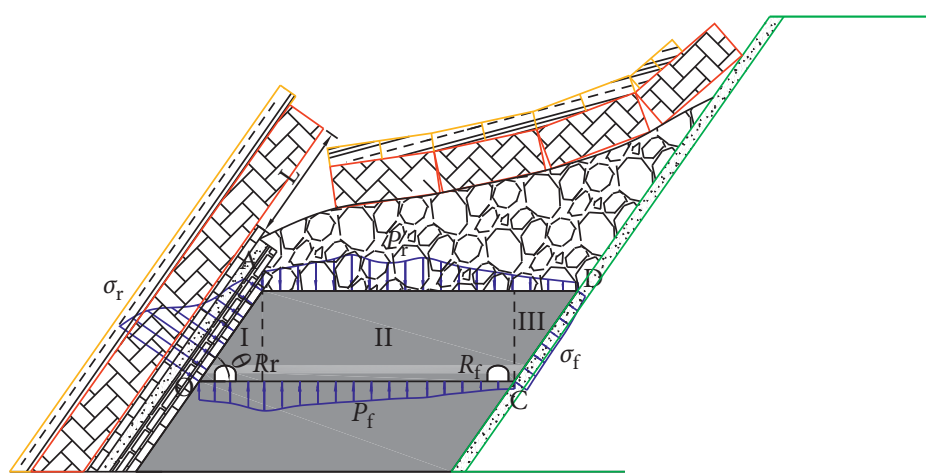

(a)

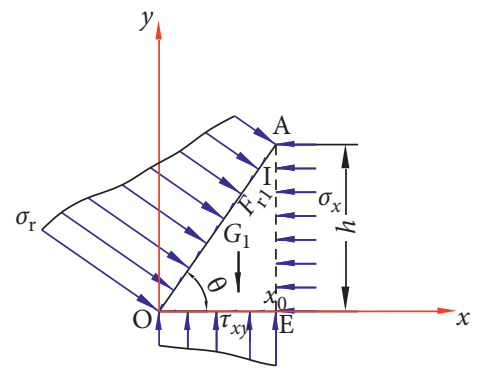

(c)

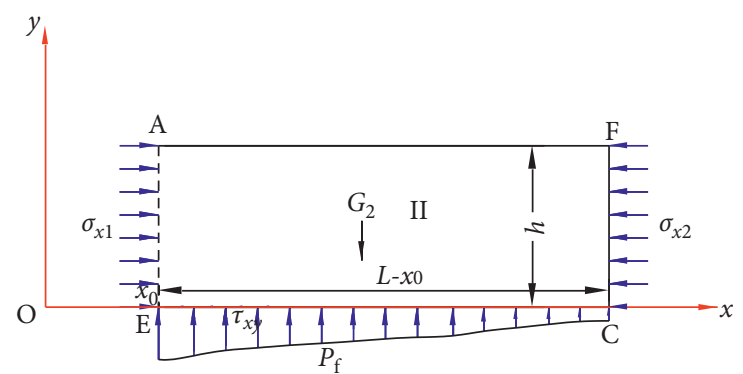

(d)

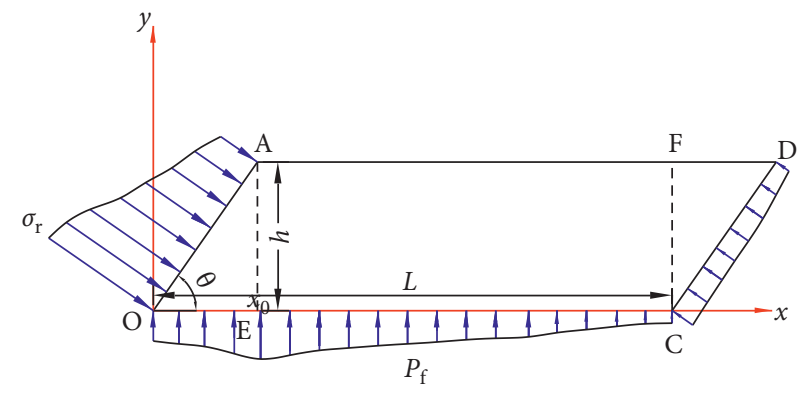

(b)

Figure 1: (a) Mechanical model for horizontal slice mining of the SICS. (b) Mechanical model for distribution of abutment pressure on the roof and stress of coal-rock in the working face. (c) Stress in the roof triangular zone. (d) Stress in the rectangular coal zone. (e) Stress in the floor triangular zone.

$$
\begin{aligned}
\sigma_{\mathrm{r}}= & \left(\frac{2 c \cdot \cos \phi}{1-\sin \phi}+\frac{1+\sin \phi}{1-\sin \phi}\left(\frac{1}{2} \gamma L \sin 2 \theta+\frac{P_{\mathrm{r}}}{\sin \theta}\right)\right) \\
& \cdot e^{(2 f((h / \sin \theta)-(x / \cos \theta))) / L \sin \theta((1+\sin \phi) /(1-\sin \phi))},
\end{aligned}
$$

where $\phi$ and $c$ denote the angle $\left({ }^{\circ}\right)$ of internal friction and the cohesion $(\mathrm{MPa})$ of coal mass. The value range of $x$ is $0 \sim h / \sin \theta$.

According to formulae (2) and (3), it can be obtained that abutment stress $P_{\mathrm{f} 1}$ of bottom coal mass in the range of $\mathrm{OE}$ is

$$
P_{\mathrm{f} 1}=\frac{\int_{0}^{h / \sin \theta} \sigma_{\mathrm{r}} \sin \theta(1+f) \mathrm{d} l_{\mathrm{OA}}+\gamma_{\mathrm{c}} h^{2} \cot \theta}{\mathrm{d} x} .
$$

Horizontal stress $\sigma_{x 1}$ is demonstrated as follows:

$$
\sigma_{x 1}=\frac{\int_{0}^{h / \sin \theta} \sigma_{\mathrm{r}} \cos \theta(1-f) \mathrm{d} l_{\mathrm{OA}}}{h} .
$$

Stress in the triangular zone on the floor is shown in Figure 1(e). It is considered that the CF boundary is subjected to uniformly distributed stress $\sigma_{x 2}$, while the CD side bears nonuniformly distributed abutment pressure $\sigma_{\mathrm{f}}$ of the floor. Moreover, $P_{\mathrm{r}}, F_{\mathrm{r} 2}$, and $G_{3}$ represent the overburden stress in the gob, frictional force between the floor and coal mass, and gravity of the triangular zone on the floor, respectively.

According to the calculation results in reference [18], the bottom plate side stress $\sigma_{\mathrm{f}}$ can be expressed as

$$
\sigma_{\mathrm{f}}=\overline{\sigma_{\mathrm{CD}}}=\gamma \overline{H_{\mathrm{CD}}} \cos \theta+\lambda \gamma \overline{H_{\mathrm{CD}}} \sin \theta .
$$

The static equilibrium equation can be established in the horizontal direction as

$$
\sigma_{x 2} \cdot h=\sigma_{\mathrm{f}} \sin \theta \cdot \frac{h}{\sin \theta}+\sigma_{\mathrm{f}} \cdot f \cos \theta \cdot \frac{h}{\sin \theta} .
$$

Substituting equation (6) into equation (7), we obtain

$$
\sigma_{x 2}=\frac{\left(\gamma \overline{H_{\mathrm{CD}}} \cos \theta+\lambda \gamma \overline{H_{\mathrm{CD}}} \sin \theta\right) \cdot(\sin \theta+f \cos \theta)}{\sin \theta} \text {. }
$$

Stress in the rectangular coal zone is demonstrated in Figure 1(d). Coal mass is subjected to horizontal stresses $\sigma_{x 1}$ and $\sigma_{x 2}$ on the left and right sides, shear stress $\tau_{x y}$ in coal mass, and self-weight $G_{2}$. The equilibrium equation for solving the stress of the rectangle yield interface is presented as follows:

$$
\left\{\begin{array}{l}
\frac{\partial \sigma_{x}}{\partial x}+\frac{\partial \tau_{x y}}{\partial y}+X=0, \\
\frac{\partial \sigma_{y}}{\partial y}+\frac{\partial \tau_{x y}}{\partial x}+Y=0, \\
\tau_{x y}=-\left(c+\sigma_{y} \tan \phi\right) .
\end{array}\right.
$$

According to relevant literature study [19], abutment stress $P_{\mathrm{f} 2}$ of the bottom coal mass and shear stress $\tau_{x y}$ in coal mass caused by horizontal stresses $\sigma_{x 1}$ and $\sigma_{x 2}$ of the rectangular zone within the $E C$ range are obtained as follows: 


$$
\left\{\begin{aligned}
P_{\mathrm{f} 2} & =\left(\frac{1}{\beta} \sigma_{x}+\frac{c}{\tan \phi}\right) e^{\left(\left(\mathrm{h} \beta \gamma-2 \tan ^{2} \phi\right) / 2 \beta\right)+(2 \tan \phi / h \beta)(L-x)} \\
& +\gamma h\left(L-\frac{h}{\tan \theta}\right), \\
\tau_{x y} & =-\left\{\left[\left(\frac{1}{\beta} \sigma_{x}+\frac{c}{\tan \phi}\right) e^{\left(\left(\mathrm{h} \beta \gamma-2 \tan ^{2} \phi\right) / 2 \beta\right)+2 \tan \phi / h \beta(L-x)}\right.\right. \\
& \left.\left.+\gamma h\left(L-\frac{h}{\tan \theta}\right)\right] \tan \phi+c\right\},
\end{aligned}\right.
$$

where $\beta$ represents the lateral pressure coefficient on the plane where ultimate strength is found and $\beta=\mu / 1-\mu$ ( $\mu$ means Poisson's ratio). By combining formulae (3)-(5), (8), and (10), distribution of abutment pressure of coal mass in the working face is obtained as follows:

$$
\left\{\begin{aligned}
P_{\mathrm{f} 1}= & \frac{\int_{0}^{h / \sin \theta} \sigma_{\mathrm{r}} \sin \theta(1+f) \mathrm{d} l_{\mathrm{OA}}+\gamma h^{2} \cot \theta}{\mathrm{d} x}\left(0<x<\frac{h}{\tan \theta}\right), \\
P_{\mathrm{f} 2}= & \left.\frac{1}{\beta} \frac{\int_{0}^{h / \sin \theta} \sigma_{\mathrm{r}} \cos \theta(1-f) \mathrm{d} l_{\mathrm{OA}}}{h}+\frac{c}{\tan \phi}\right) \\
& \cdot e^{\left(\left(h \beta \gamma-2 \tan ^{2} \phi\right) / 2 \beta\right)+(2 \tan \phi / h \beta)(L-x)} \\
& +\gamma h\left(L-\frac{h}{\tan \theta}\right)\left(\frac{h}{\tan \theta}<x<L\right) .
\end{aligned}\right.
$$

Figure 2 shows the curve of stress distribution function of the working face obtained according to formula (11). The dip angle $\theta$ of the coal seam is set as $60^{\circ}$, and the height $h$ of a slice is $17.2 \mathrm{~m}$. The working face is $60 \mathrm{~m}$ in length $L$. Moreover, Poisson's ratio $\mu$, the frictional coefficient $f$, the cohesion $c$, and the angle $\phi$ of internal fraction, respectively, are $0.325,0.5,3.62 \mathrm{MPa}$, and $33^{\circ}$.

As shown in Figure 2, under the influences of roof stress, the static stress of the $R_{\mathrm{r}}$ is $27 \sim 44 \mathrm{MPa}$, which is obviously higher than that $(10 \sim 14.5 \mathrm{MPa})$ of the $R_{\mathrm{f}}$. Coal burst hazards of the $R_{\mathrm{r}}$ are more serious under pure static loads. High static stress of the $R_{\mathrm{r}}$ provides the basis of static loads for coal burst.

\subsection{Distribution Characteristics of Dynamic Stress Released by} RoofBreakage. During top coal caving in horizontal slices of the SICS, large quantities of coal were mined out. When noncritical strata like immediate roof were thin, the caving roof showed a low filling degree to the gob and a large free space was left in the mined-out space so that hard key strata were suspended, thus forming an upturned structure of the cantilever beam, as demonstrated in Figure 1(a). By simplifying rock mass in fractured key strata into a beam structure, a model of the cantilever beam of key strata was established, as shown in Figure 3.

In Figure $3, L_{\mathrm{r}}, h, q$, and $\omega$, respectively, indicate the length, thickness, self-weight load, and deflection before breakage of key strata. One end of the hanging key strata can be considered to be fixed before they are fractured and the production of deflection and bending moment is mainly affected by normal load.

The maximum bending moment of the cantilever beam at the fixed end is obtained as follows:

$$
M=\frac{q \cos \theta L_{\mathrm{r}}^{2}}{2} .
$$

The maximum tensile stress of the beam appears on the upper surface of the fixed end. When tensile stress exceeds tensile strength $R_{\mathrm{T}}$, the beam is fractured at this position, namely,

$$
\sigma=\frac{M h}{2 I} \leq R_{\mathrm{T}}
$$

When stress in the fixed end exceeds tensile strength of rock, beam is about to be fractured, thus meeting the following condition:

$$
\sigma=\frac{M y}{I}=\frac{M h}{2 I} \leq R_{\mathrm{T}} .
$$

By combining formulae (12) and (13), periodic fracture torque of the cantilever beam is shown as follows:

$$
L_{\mathrm{r}}=h \sqrt{\frac{R_{\mathrm{T}}}{3 q \cos \theta}} .
$$

According to the mechanics of materials, bending deformation of the cantilever beam due to self-weight load is presented as follows:

$$
\omega_{\mathrm{q}}=-\frac{q \cos \theta x^{2}}{24 E I}\left(x^{2}-4 L_{\mathrm{r}} x+6 L_{\mathrm{r}}^{2}\right) .
$$

In accordance with the reciprocal quantification of work, the accumulated energy when the cantilever beam fractures is

$$
U=\int_{0}^{L_{\mathrm{r}}} \omega_{\mathrm{q}} q \cos \theta \mathrm{d} x=\frac{(q \cos \theta)^{2} L_{\mathrm{r}}^{5}}{20 E I} .
$$

Based on previous research results $[18,20]$, the relationship between dynamic load applied on a certain point in the mining space and energy released from roof breakage is demonstrated as follows:

$$
\sigma_{\mathrm{d}}=0.0645 \rho \cdot C \cdot U^{0.3566} \cdot l_{\mathrm{d}}^{-\eta},
$$

where $\rho, C, l_{\mathrm{d}}$, and $\eta$ indicate the medium density, the propagation velocity of shock waves, the distance between a certain point and the hypocenter, and the attenuation coefficient of shock waves.

For formula (18), medium density $\rho$, velocity of shock waves $C$, length of the main key stratum and main roof breakage $L$, and uniformly distributed stress $q$, respectively, are $2,500 \mathrm{~kg} / \mathrm{m}^{3}, 4,000 \mathrm{~m} / \mathrm{s}, 150 \mathrm{~m}, 32 \mathrm{~m}$, and $12.5 \mathrm{MPa}$. 


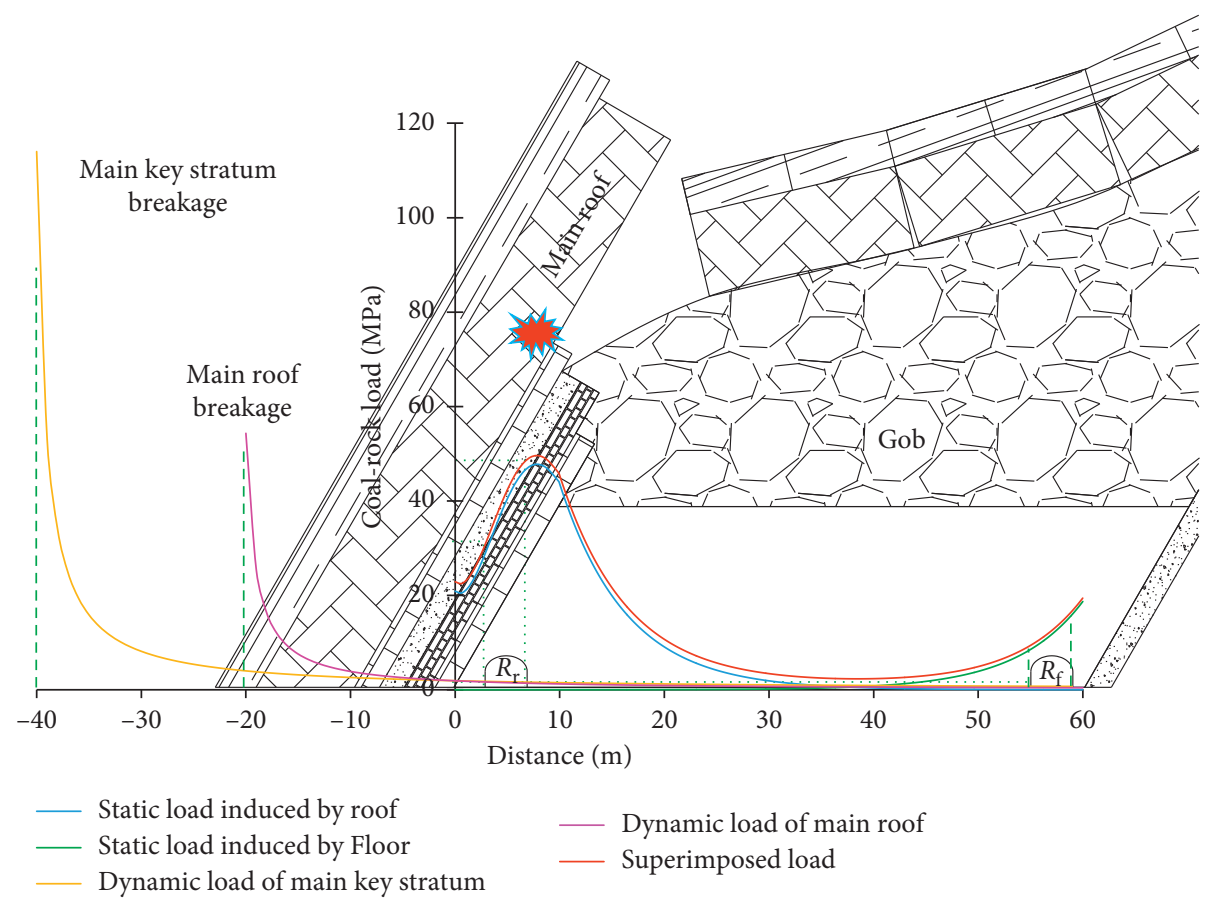

FIGURE 2: Distribution of dynamic load induced by roof breakage and static stress of the working face.

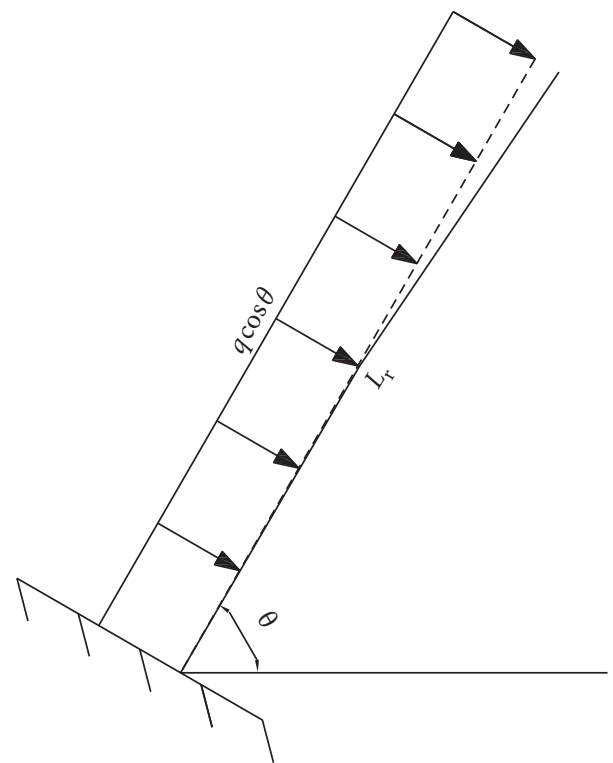

FIGURE 3: Mechanical model for roof breakage with the cantilever beam.

Moreover, the dip angle of the roof $\theta$ and attenuation coefficient of shock waves $\eta$ are $60^{\circ}$ and 1.1 , respectively. The distance $l$ from the hypocenter of the main key stratum and main roof to the coal seam is $40 \mathrm{~m}$ and $20 \mathrm{~m}$. Given the above parameters, the distribution curve of dynamic stress with propagation distance is obtained, as shown in Figure 3. In the meanwhile, by combining with formula (11), the distribution curve of superposed dynamic and static stress of coal and rock in the working face is obtained.

Based on the distribution curve of dynamic stress, it can be seen that dynamic load attenuates fast in the transfer process. When the hypocenter is close to the roadway, disturbance is large; otherwise, disturbance is small. Because of special occurrence structure of the SICS, the floor is less significantly fractured, and dynamic load mainly comes from the roof. After stress superposition, the stress of the $R_{\mathrm{r}}$ is $29 \sim 45 \mathrm{MPa}$, while that of the floor is $10.2 \sim 14.7 \mathrm{MPa}$, and the stress difference between the $R_{\mathrm{r}}$ and the $R_{\mathrm{f}}$ increases, so the $R_{\mathrm{r}}$ is more vulnerable to coal burst when being affected by superposed load.

\section{Similarity Simulation Test under Superposition of Dynamic and Static Loads}

Through the above theoretical analysis, high static stress in the $R_{\mathrm{r}}$ zone caused by the hanging thick and hard roof and dynamic load produced by roof breakage during mining of the SICS are a stress basis for coal burst occurrence in the $R_{\mathrm{r}}$. This chapter designed the test on the background of actual geological condition and superposition characteristics of static loads and roof dynamic loads and then further explored the laws of coal-rock mass deformation and coal burst in the SICS.

3.1. Test Apparatus. The test apparatus including a control console, a dynamic loading system, a static loading system, and a model support is shown in Figure 4 . The dimension of the model support is $1.6 \mathrm{~m} \times 0.4 \mathrm{~m} \times 1.2 \mathrm{~m}$.

3.1.1. Dynamic Load. The console controls the pendulum to lift to the preset height around the axis of rotation, and then it strikes the incident pole after free falling. The pendulum weighs $20 \mathrm{~kg}$, and length of the pendulum rod is $1 \mathrm{~m}$. 


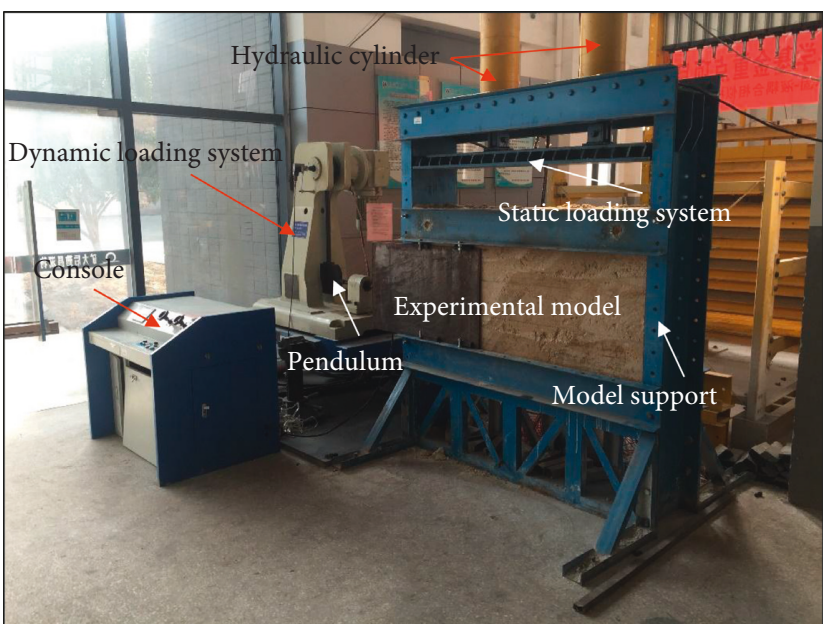

(a)

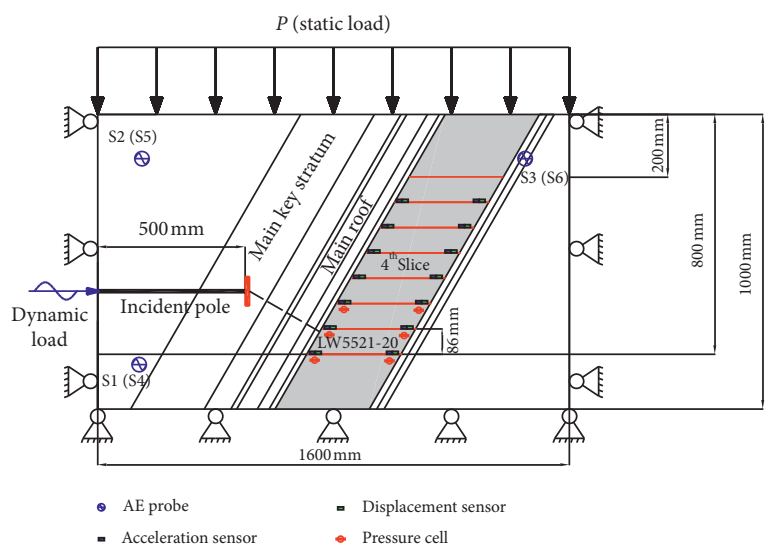

(b)

Figure 4: Similarity simulation test bench under superimposed dynamic and static load. (a) Physical picture of the test apparatus. (b) Design of the test model.

Dynamic energy is transferred to the location set for the loading source in the model through the pole. Because the size of the loading source can be neglected relative to that of the overall model, dynamic load is applied in the form of point source and transferred outward [21, 22].

3.1.2. Static Load. Two hydraulic cylinders are connected to a loading plate on the upper part of the model. After the loading plate contacts the model, the pressures of the hydraulic cylinders rise to the preset static load and are uniformly distributed on the upper part of the model, thus simulating gravity stress of the upper rock strata of the model; in the whole test process, static stress is in the state of pressure maintenance.

3.2. Similarity Ratio in the Test. The test was designed based on similarity theory, and the Froude proportionality factor was selected as a benchmark coefficient [23-25]. The similarity ratios of geometry and density of the model were 200 : 1 and $1.67: 1$, as shown in Table 1 . The similarity ratios of other parameters could be determined according to the scale relation.

The parameters for building the model are demonstrated in Table 2.

3.3. Test Monitoring Equipment and Layout. Seven slices, each with the height of $86 \mathrm{~mm}$, were arranged in the vertical direction of the coal seam in the model. Dynamic load is applied, and test data are obtained after each slice is excavated. The pendulum is subjected to $0.1 \mathrm{~m}$ (simulated energy is $1.30 \times 10^{6} \mathrm{~J}$ ) gradient cyclic loading. The maximum height of the pendulum in the first 6 slice tests is $0.5 \mathrm{~m}\left(6.50 \times 10^{6} \mathrm{~J}\right)$, and the pendulum in the $7^{\text {th }}$ slice test rises step by step until the coal and rock are destroyed. The test monitoring system included a DH960 superdynamic signal test and analysis system, a PIC-2 AE system, a Memrecam GX-3 high-speed
TABLE 1: Scale factors and values of the major variables.

\begin{tabular}{lcc}
\hline Major variable & Froude scale factor & Value \\
\hline Length & 1 & 200 \\
Density & $\rho$ & 1.667 \\
Acceleration & $a$ & 1 \\
Time & $t=\sqrt{l}$ & 14.14 \\
Stress & $\sigma=\rho l$ & 333 \\
Strain & $\varepsilon$ & 1 \\
Poisson's ratio & $\mu$ & 1 \\
Friction angle & $\phi$ & 1 \\
Speed & $v=\sqrt{l}$ & 14.14 \\
Energy & $w=\rho l^{2}$ & $6.6 \times 10^{4}$ \\
\hline
\end{tabular}

Table 2: Proportion of similar material.

\begin{tabular}{lccc}
\hline Lithology & $\begin{array}{c}\text { Width } \\
(\mathrm{cm})\end{array}$ & $\begin{array}{c}\text { Simulated } \\
\text { strength }(\mathrm{kPa})\end{array}$ & $\begin{array}{c}\text { Compressive } \\
\text { strength }(\mathrm{MPa})\end{array}$ \\
\hline Average strength roof & 40 & 93 & 31 \\
Oil shale & 25 & 84 & 28 \\
Oil shale and sandstone & 9 & 120 & 40 \\
Oil shale & 2 & 84 & 28 \\
Aluminum mudstone & 7 & 54 & 18 \\
Oil shale & 4 & 84 & 28 \\
Fine sandstone & 2 & 135 & 45 \\
Coal & 32 & 46 & 15 \\
Carbon mudstone & 5 & 54 & 18 \\
Siltstone & 5 & 114 & 38 \\
Average strength floor & 29 & 93 & 31 \\
\hline
\end{tabular}

camera, and pressure cells [26], and the layout is shown in Figure 5 .

3.4. Results and Analysis. The height of the pendulum in the test of $1 \sim 6$ slices varies from $0.1 \mathrm{~m}$ to $0.5 \mathrm{~m}$, and coal and rock vibrate elastically without obvious deformation and failure. However, when height of the pendulum in the test of 


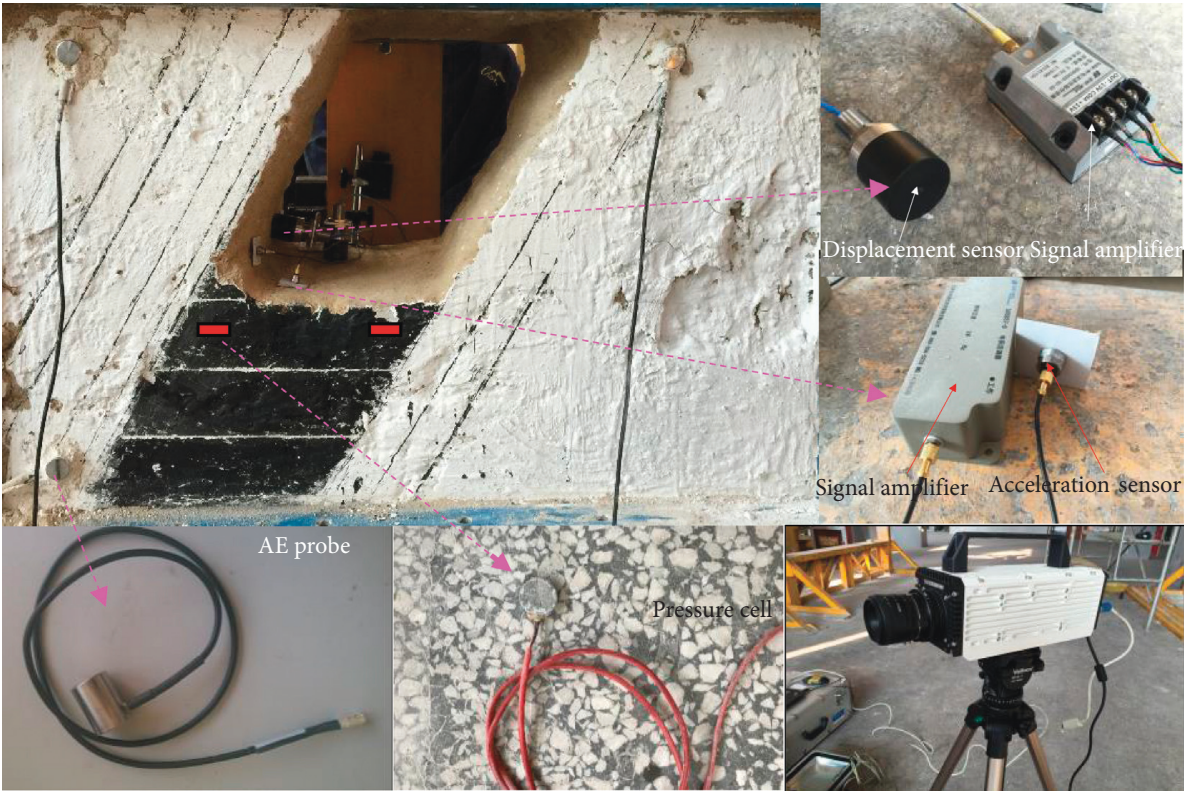

FIgURE 5: Monitoring equipment and layout.

slice 7 is $0.6 \mathrm{~m}$, dynamic failure occurs on the $R_{\mathrm{r}}$ and coal and rock are instantaneously thrown out into the mined-out space.

3.4.1. Response Characteristics of AE. AE signals in coal-rock mass are a kind of elastic waves generated by sudden release of the energy accumulated by microfracture and have ability of predicting materials and structural instability [27, 28]. Their positioning results can directly reflect the process of crack initiation, propagation, and connection in coal-rock mass.

In Figure 6, AE events mainly concentrate on roof and coal mass. This accurately reveals appearance of breakage of coal and rock after applying dynamic loads. During transfer of shock waves, coal and rock media in lower strata vibrate and develop fractures.

During the test on $1^{\text {st }}$ and $2^{\text {nd }}$ slices, because the stress of the coal sample is relatively low and the distance from the hypocenter is relatively far, $\mathrm{AE}$ events with small energy $(<50 \mathrm{~dB})$ are dominant. In the test process of slices $3 \sim 6$, with the mining of the working faces, the distance from the hypocenter is shorter, while static stress and the number and energy of $\mathrm{AE}$ events rise (events larger than the $50 \mathrm{~dB}$ increase). Moreover, the roof in lower strata develops more fractures so that energy is released more violently and coal burst hazard increases. In the test of the $7^{\text {th }}$ slice, $\mathrm{AE}$ events with large energy dramatically increase and a single AE event has more energy (there are four AE events with energy larger than $50 \mathrm{~dB}$ ).

Figure 7 shows tomographic images of AE shock waves in the test. For sections in the vertical or horizontal directions in the figure, abnormal area of high wave velocity is located in main key strata. Furthermore, in coal mass close to the roof side in $6^{\text {th }}$ and $7^{\text {th }}$ slices, the maximum wave velocity in main key strata reaches $4.52 \mathrm{~km} / \mathrm{s}$ and the peak wave

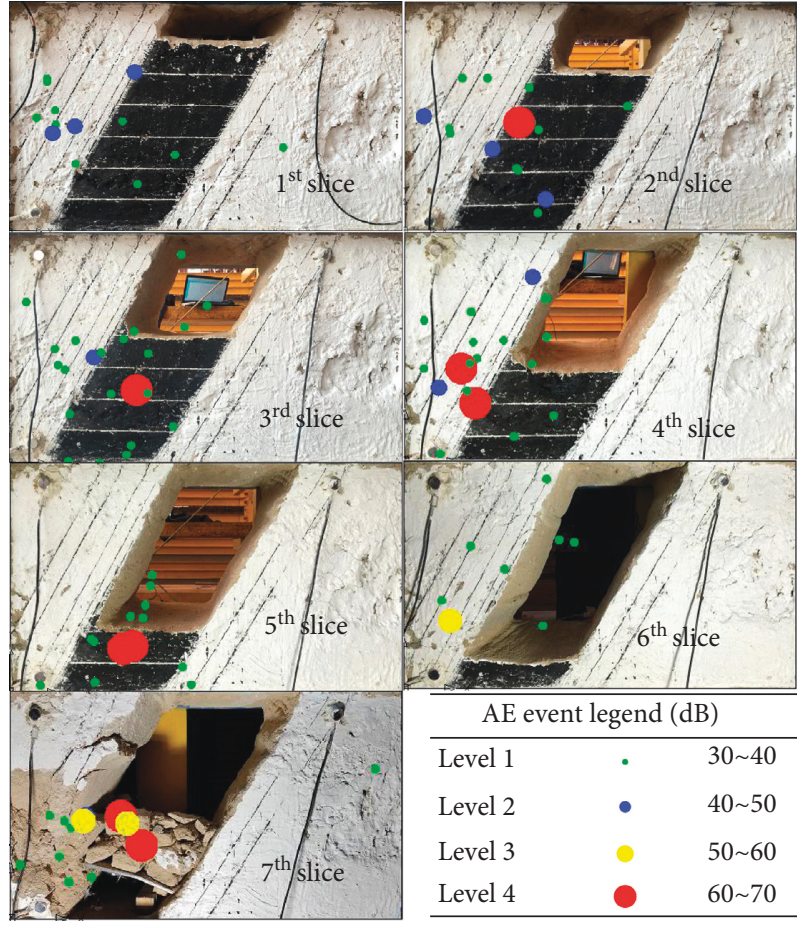

FIgURE 6: AE positioning results in the test of each slice.

velocity in coal mass is $3.93 \mathrm{~km} / \mathrm{s}$. According to the directly proportional relationship between wave velocity and stress [29], the larger the wave velocity, the higher the stress. This indicates that because of effects of the occurrence structure on the test, stress of coal mass in main key strata and on the roof side of lower slices is higher, which is well coupled with theoretical analysis results. In the dynamic loading process, coal burst easily happens in coal mass on the roof side of lower slices. 


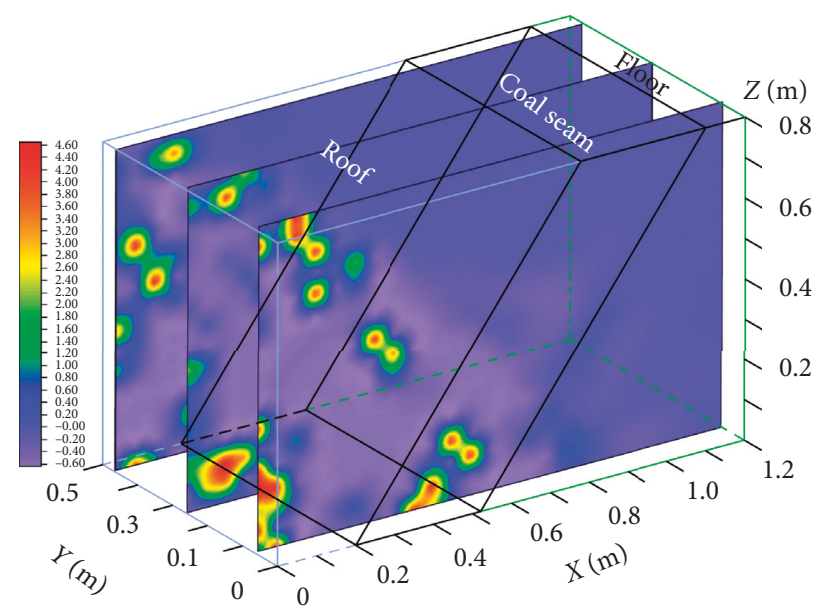

(a)

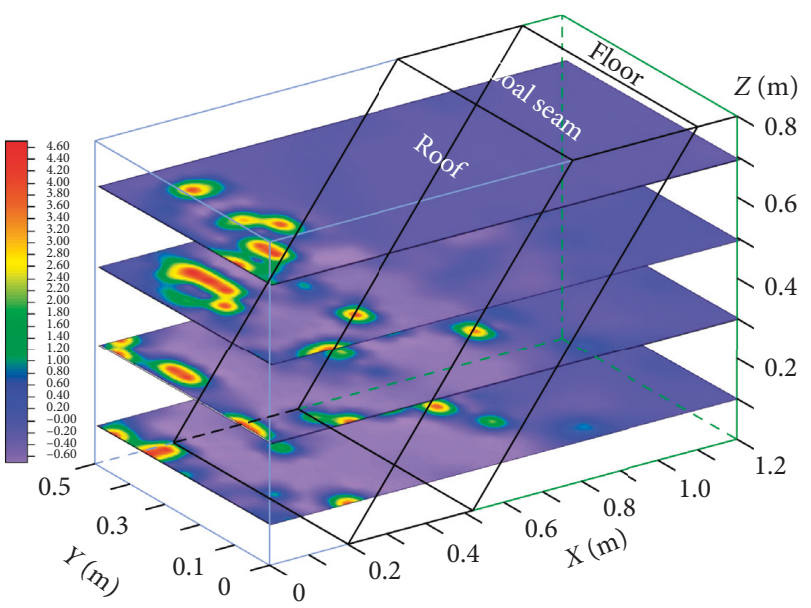

(b)

FIgURE 7: Tomography results in the test. (a) AE velocity distribution in the vertical direction. (b) AE velocity distribution in the horizontal direction.

3.4.2. Response Characteristics of Static Stress. In the test, pressure cells were separately arranged in bottom coal mass in $5^{\text {th }}, 6^{\text {th }}$, and $7^{\text {th }}$ slices close to roof and floor sides so as to measure changes of static stress before and after mining slices.

Figure 8 demonstrates distribution of static stress on roof and floor sides before and after slice mining. It can be seen from the figure that stress on the roof side is obviously higher than that on the floor side in the same horizontal slice. In addition, stresses on the roof side before slice mining are $0.039,0.033$, and $0.030 \mathrm{MPa}$ higher than those on the floor side, while stresses on the roof side after slice mining are $0.082,0.074$, and $0.074 \mathrm{MPa}$ higher than those on the floor side. Before mining the upper slices, stress on roof and floor sides increases with the rise of burial depth. After mining, stress on the roof side rises and the maximum increased amplitude of stress is found in slices under mining, showing a rising trend on the whole. However, stress on the floor side slightly reduces and shows a decrease trend on the whole.

According to pressure cells' data, consistent with theoretical analysis results, stress on the roof side is obviously higher than that on the floor side, indicating that the test can reflect the actual deformation and failure of coal and rock in the field to some extent. Stress on the roof side slightly increases after mining the upper slices, demonstrating that the increase of the mining range in the strike before breakage of hard key strata can lead to the rise of the stress concentration degree in the roof of the roadway, which greatly raises coal burst hazards.

3.4.3. Response Characteristics of Acceleration. After dynamic loading occurs, it propagates in coal-rock media in the form of shock waves, resulting in vibration and deformation of coal-rock. The stress and deformation of the coal-rock produce instantaneous acceleration, so it can reflect the instantaneous state of movement and deformation of the coal-rock subjected to dynamic load disturbance to some extent. Slices 5, 4, 6, 7, 3, 2, and 1 are ranked in a rising order according to their distances to the source.

In Figure 9, in (9) and (10, accelerations of the roof and floor restore stability after transient vibration and the whole vibration process is no more than $0.1 \mathrm{~s}$, so dynamic loading is instantaneous. In the vibration process, acceleration firstly increases to the positive peak and then decreases to the zero point and continues to rise to the negative peak. After that, it continuously vibrates in the reverse direction. Dynamic loading is a process of repeated tension and compression, and vibration can be only induced in the elastic deformation stage of coal and rocks. When simulated energy is $7.80 \times 10^{6} \mathrm{~J}$, coal and rocks are damaged and acceleration in the negative direction of the roof is small, indicating that instantaneous breakage failure of coal and rock occurs at this stage and tensile dynamic stress is small.

With the increase of dynamic energy, peak acceleration linearly rises. Peak acceleration of the $R_{\mathrm{r}}$ is obviously larger than that of the $R_{\mathrm{f}}$. Shock waves gradually attenuate with the increase of propagation distance, resulting in the gradually reduced deformation degree of coal and rock. By taking the pendulum at the height of $0.4 \mathrm{~m}$ as an example, it can be seen that peak acceleration of the roof in the $5^{\text {th }}$ slice reaches the largest value and is $718.72 \mathrm{~mm} / \mathrm{s}^{2}$, while those of slices $1 \sim 7$, respectively, are $25.03 \%, 14.55 \%, 41.74 \%, 59.77 \%, 76.12 \%$, and $55.61 \%$ that of the $5^{\text {th }}$ slice.

Propagation distance from the $4^{\text {th }}$ slice to the source of dynamic loads is smaller than those from $6^{\text {th }}$ and $7^{\text {th }}$ slices, while peak accelerations of the $6^{\text {th }}$ and $7^{\text {th }}$ slices are larger. When the simulated energy is $5.2 \times 10^{6} \mathrm{~J}$ and $6.5 \times 10^{6} \mathrm{~J}$, the peak acceleration of the $5^{\text {th }}$ slice is larger than that causing sudden failure in the $7^{\text {th }}$ slice, while failure is not found in the $5^{\text {th }}$ slice and static stress in the $7^{\text {th }}$ slice is higher. By combining with previous distribution laws of static stress of coal and rocks, static stresses in the $6^{\text {th }}$ and $7^{\text {th }}$ slices are obviously higher than that in the $4^{\text {th }}$ slice and concentration degree is higher. Moreover, stress is higher after superposition of dynamic and static loads. This indicates that, in the 

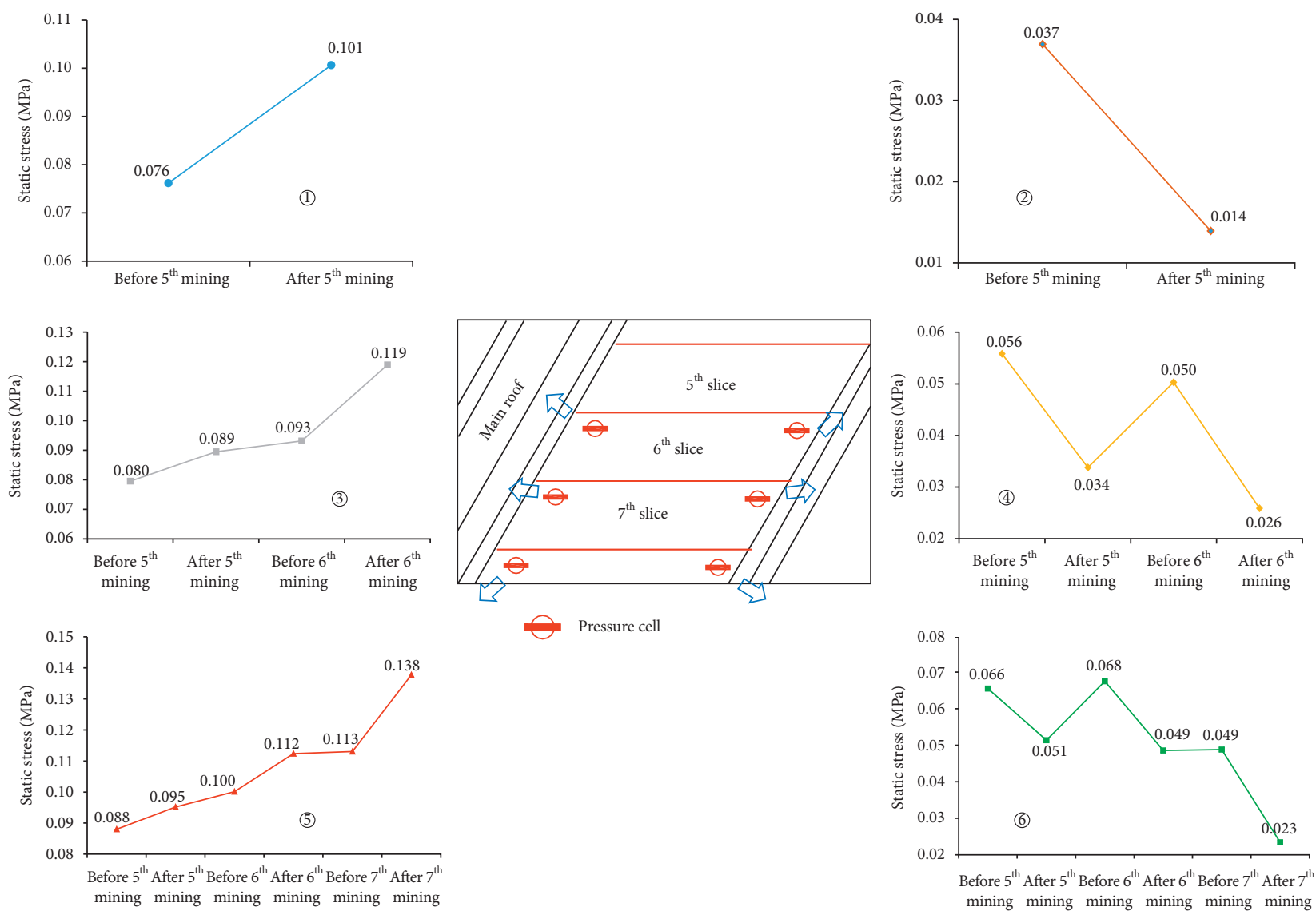

Figure 8: Monitoring results of static stress on roof and floor sides before and after slice mining.

bearing capacity of coal and rocks, when the static load stress is higher, the dynamic load stress required to cause the instantaneous failure is smaller.

\section{A Case Study}

4.1. Basic Conditions of the Panel. Yaojie No. 3 coal mine located in Lanzhou City, Gansu Province, China, belongs to a typical mine applying horizontal slice top-coal caving in an SICS. The 2\# coal seam with the thickness of $0 \sim 109.88 \mathrm{~m}$ (the average was $27.41 \mathrm{~m}$ ) was primary mined. The long wall (LW) 5521-20 panel located in the No. 5 mining area where 19 slices had been mined was the $20^{\text {th }}$ slice with the burial depth being about $500 \mathrm{~m}$. The panel extended $1,020 \mathrm{~m}$ along the strike, and the inclination angle of the coal seam was $45 \sim 62^{\circ}$ with an average of $55^{\circ}$. The slice of the panel was $17.2 \mathrm{~m}$ in thickness. To facilitate ventilation and transportation, three systems with the length of 395, 365, and $260 \mathrm{~m}$ were arranged for the panel, as shown in Figure 10.

A borehole histogram from prospecting hole 527 in the mining area is shown in Figure 11. The average thickness of the coal seam of the LW5521-20 panel was $54.77 \mathrm{~m}$. For overlying strata on the roof of the coal seam, the lithology of the main roof and the main key stratum was both oil shale with an average thickness of $6.68 \mathrm{~m}$ and $43.88 \mathrm{~m}$. As for underlying strata on the floor of the coal seam, the immediate floor and the main floor were carbon mudstone and gritstone, and their thickness was $1.0 \mathrm{~m}$ and $1.99 \mathrm{~m}$, respectively.

4.2. Monitoring Measures. Since November 2015, a seismic monitoring system called SOS, developed by the Central Mining Institute of Poland, has been installed in the Yaojie No. 3 colliery to collect and filter seismic signals. SOS includes a real-time monitoring recorder, an analyzer, verticalcomponent geophones, and a digital transmission system. The SOS MS monitoring system can dynamically and automatically monitor signals of mine earthquakes in mines in real time. Through data processing, the time, energy, and three-dimensional coordinates of the vibration with energy greater than $100 \mathrm{~J}$ can be calculated, and the type of each vibration can be determined. Moreover, the force source of coal burst can be judged, thus evaluating the risk of coal burst. There were a total of 14 geophones distributed around the colliery, and five were close to LW5521-20, including Nos. 4, 5, 6, 7, and 8 (Figure 10).

4.3. Seismic Events and Tomography. Since there is an exponential function correlation between $\mathrm{P}$-wave velocity and axial stress in coal and rocks, stress states and high seismic hazard zones during mining can be assessed by periodic velocity tomography imaging [29-31]. Positive velocity 

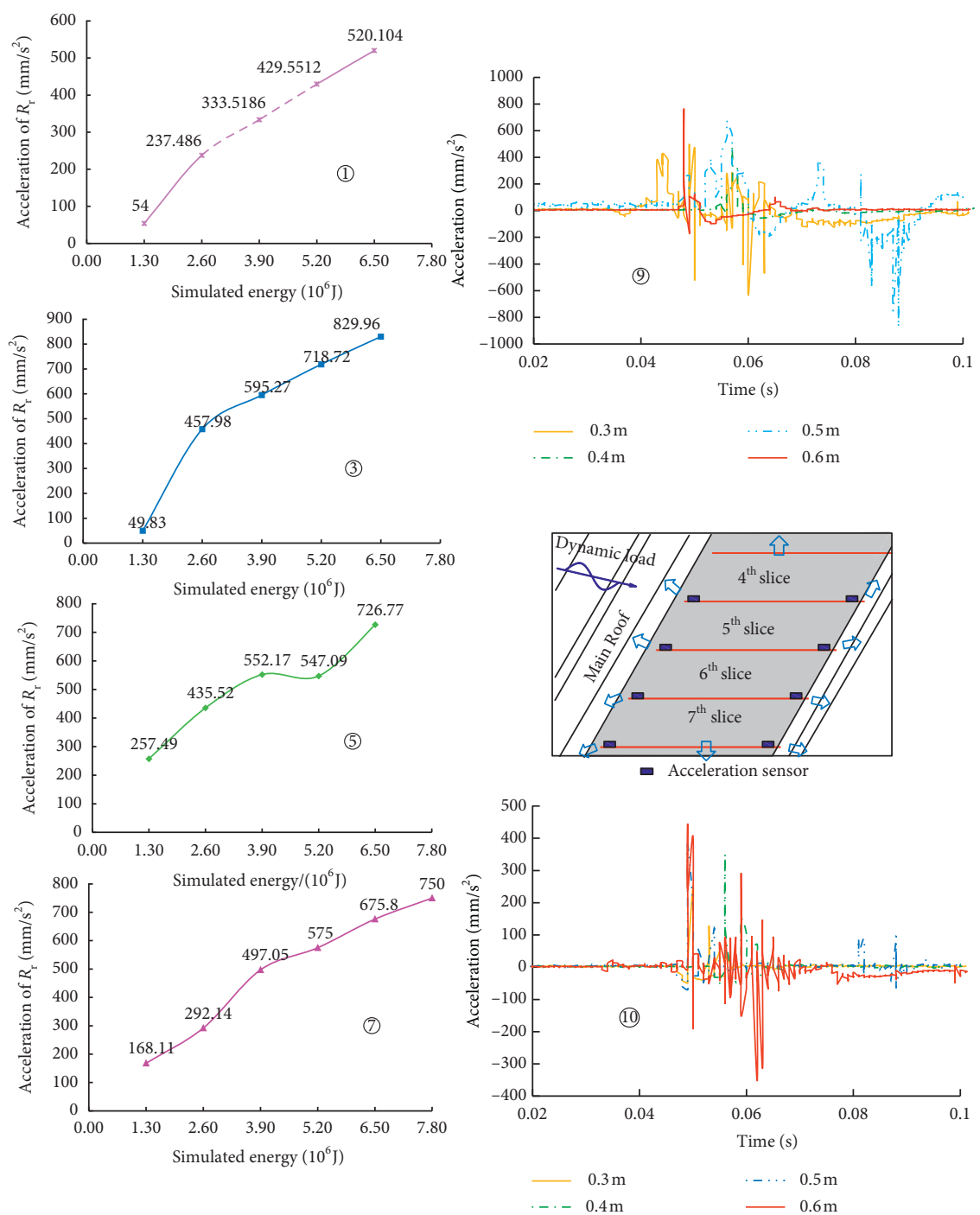
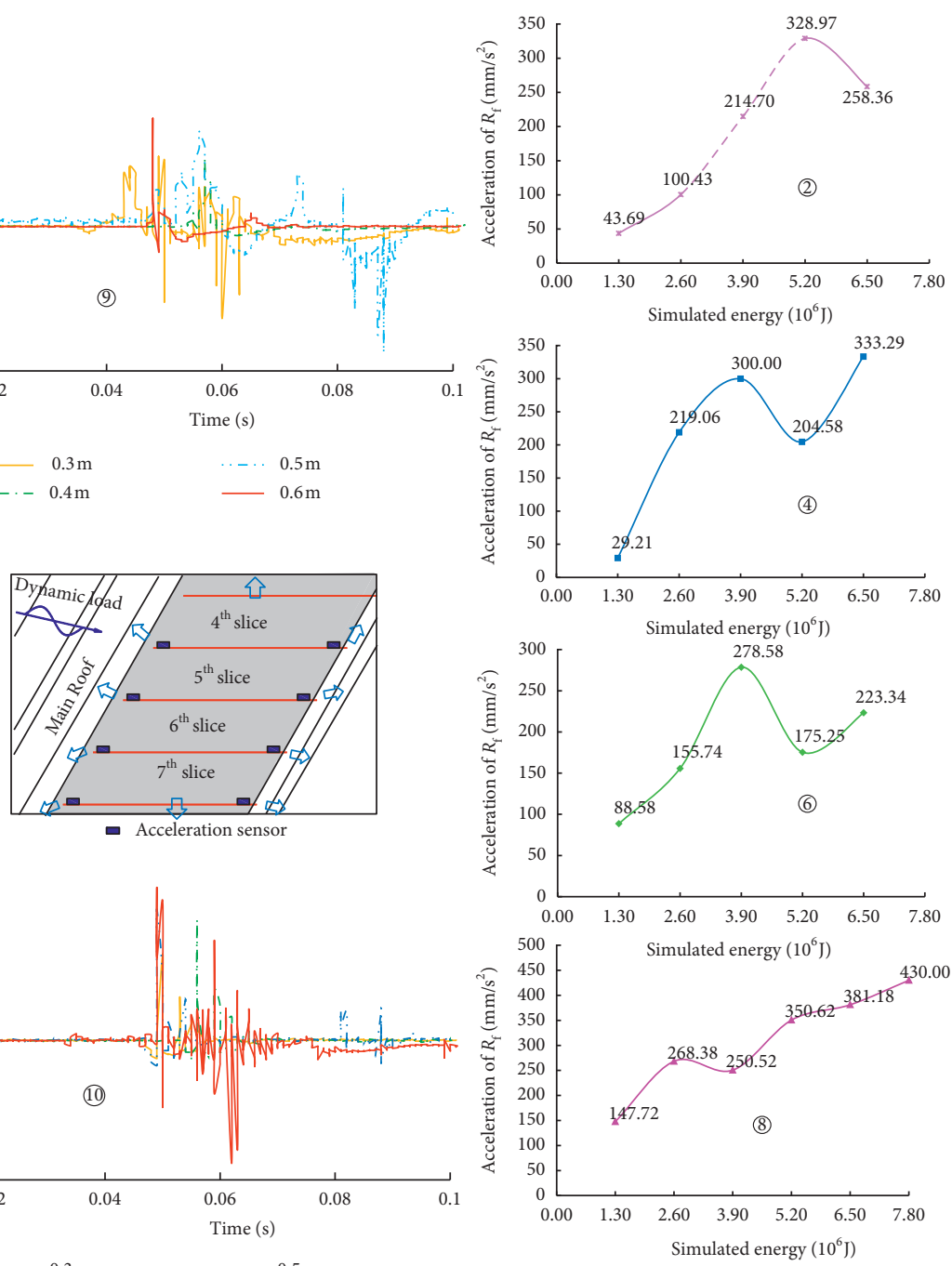

Figure 9: Characteristic curves of acceleration response.

anomaly $\left(A_{\mathrm{n}}\right)$ and the value to express the variation degree of velocity gradient (VG) are shown as follows $[32,33]$ :

$$
\left\{\begin{array}{l}
A_{\mathrm{n}}=\frac{v_{\mathrm{p}}-v_{\mathrm{p}}^{a}}{v_{\mathrm{p}}^{a}}, \\
\mathrm{VG}=v_{\mathrm{p}} \mathrm{Grad}
\end{array}\right.
$$

where $v_{\mathrm{p}}, v_{\mathrm{p}}^{a}$, and Grad indicate the P-wave velocity $(\mathrm{m} / \mathrm{s})$ at a certain point, the average wave velocity $(\mathrm{m} / \mathrm{s})$ in the inversion zone, and the change gradient $(1 / \mathrm{s})$ of wave velocity at a certain point, respectively.

The relationship between the wave velocity anomaly and the stress concentration level is stipulated in Table 3, and the relationship between the VG value and the coal burst hazard level is shown in Table 4. Based thereon, the potential rock burst hazard can be forecast by passive velocity tomography.

There are one MS event with the energy larger than $10^{5} \mathrm{~J}$, two events with the energy of $10^{4} \sim 10^{5} \mathrm{~J}$, and 28 events with the energy of $10^{3} \sim 10^{4} \mathrm{~J}$ within the zone of the 5521-20 panel.
Distribution characteristics of MS events are consistent with distribution laws of $\mathrm{AE}$ events in the test in Section 3.

MS events are mainly monitored on the roof, and all events with large energy (greater than $10^{4} \mathrm{~J}$ ) are found on the roof, indicating that the roof is deformed and fractured layer by layer with the mining of the working face and a lot of energy is released and transferred to surrounding rocks of the $R_{\mathrm{r}}$ after breakage of the thick and hard roof. Additionally, the coal burst happens when the stress exceeds the loading limit of coal and rock after the dynamic loads superpose with high static stress of the $R_{\mathrm{r}}$. The floor side witnesses few MS events which release lower energy, and the floor is deformed and damaged at a relatively lower degree, which slightly affects dynamic loads produced by coal mass. Through comparison, MS events in the field are consistent with AE results obtained in the test, which reflects the accuracy of the test.

Figure 12 presents tomographic results from June 1 to 30. The selected section of the working face can better reflect stresses on the roof and floor in the SICS, and seismic data 


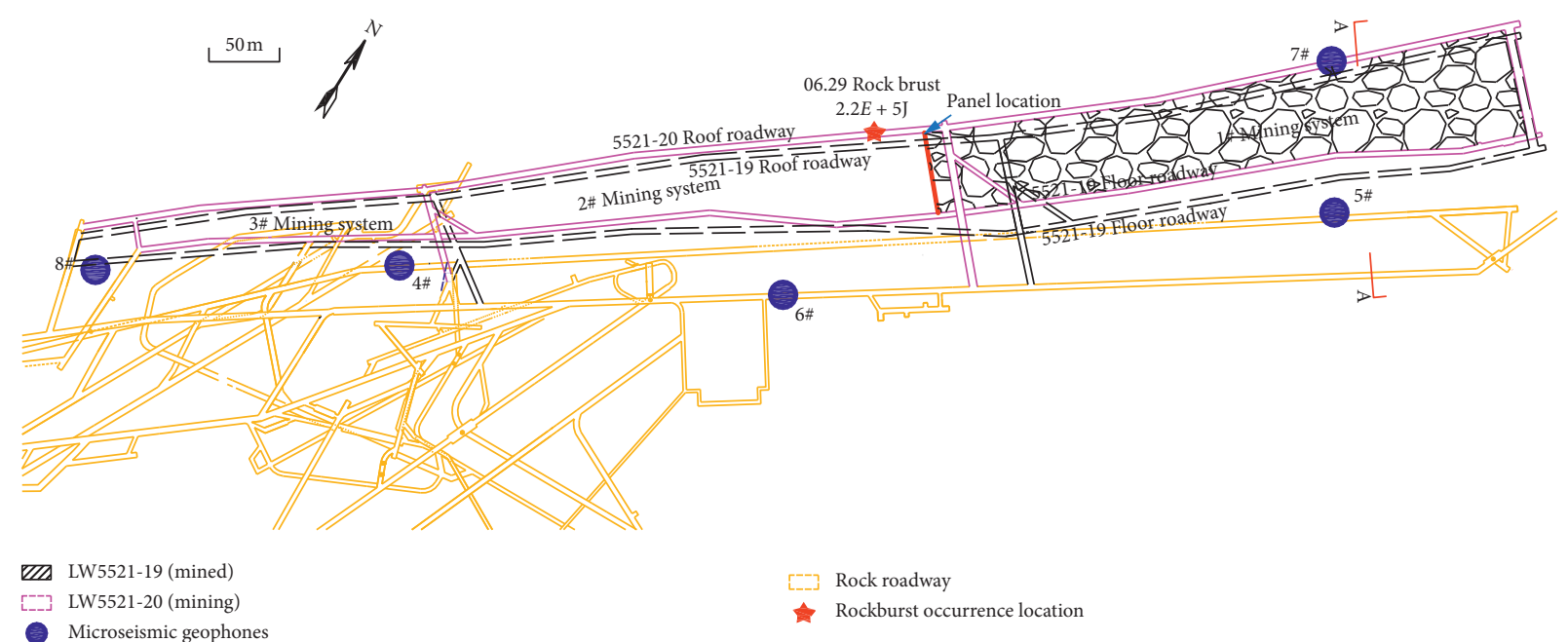

(a)

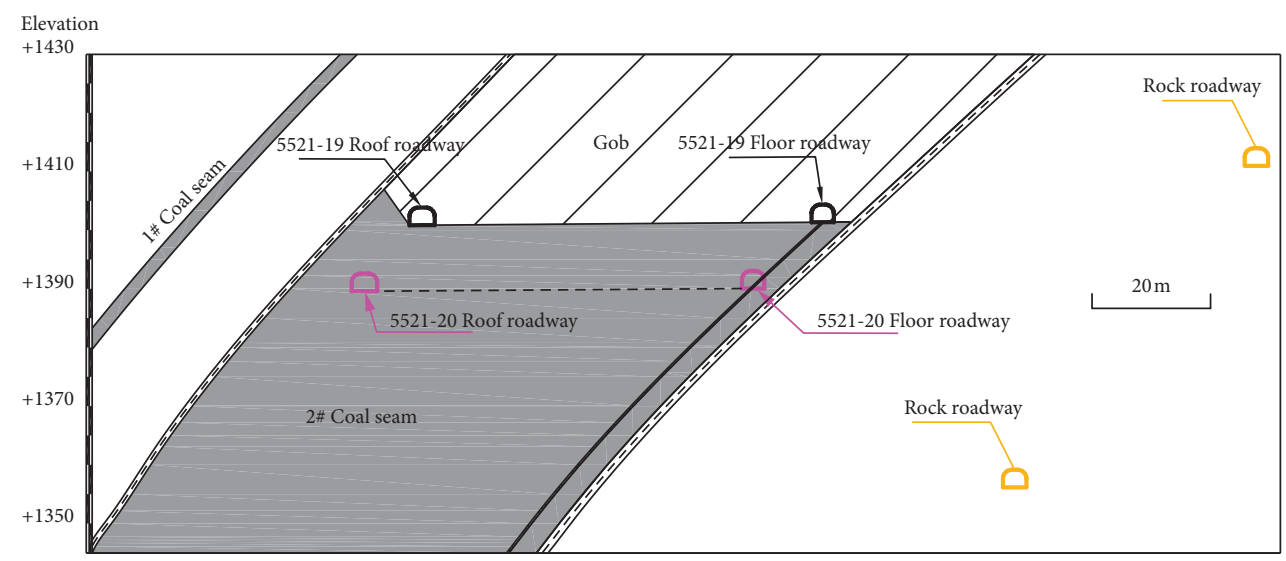

(b)

FIGURE 10: Layout and profile of the LW5521-20 panel. (a) Layout of the LW5521-20 panel. (b) A-A profile.

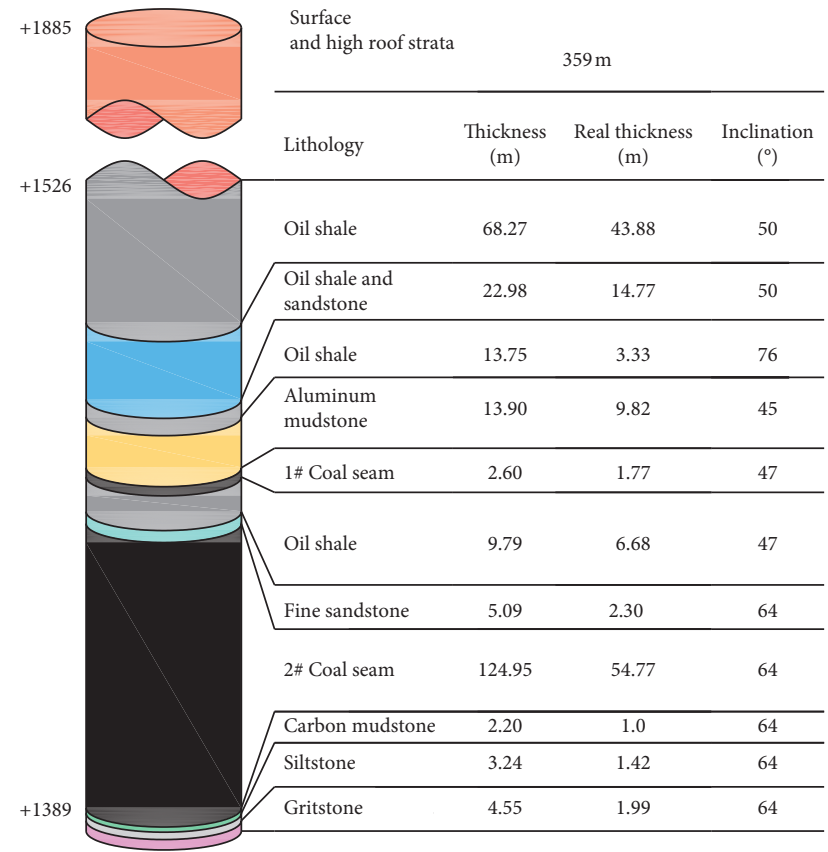

FIgURE 11: Histogram of 527\# prospecting hole.
TABLE 3: Relation between the wave velocity anomaly and the stress concentration level.

\begin{tabular}{lcc}
\hline $\begin{array}{l}\text { Coal burst } \\
\text { risk index }\end{array}$ & $\begin{array}{c}\text { Stress concentration } \\
\text { level }\end{array}$ & $\begin{array}{c}\text { Wave velocity } \\
\text { anomaly } A_{\mathrm{n}}(\%)\end{array}$ \\
\hline 0 & None & $<5$ \\
1 & Weak & $5 \sim 15$ \\
2 & Moderate & $15 \sim 25$ \\
3 & Strong & $>25$ \\
\hline
\end{tabular}

from LW5521-20 acquired by five nearby geophones $(4,5,6$, 7 , and 8) were used for tomographic calculations. In the figure, the maximum abnormal coefficient $A_{\mathrm{n}}$ on the roof side is 0.71 and the maximum abnormal coefficient of wave velocity gradient reaches 1.08 , both in the strong level.

In Figure 12(a), by comparing CT results with the distribution curve of static stress in theoretical calculation, when stress along the working face develops from the $R_{\mathrm{r}}$ to the $R_{\mathrm{f}}, A_{\mathrm{n}}$ gradually reduces in the range of $0.5 \sim 0.3 \sim 0.1$ and the results in cloud pictures of stress are well coupled with stress distribution curves, so the accuracy of theoretical analysis can be verified by field data. 
TABLe 4: Relation between the VG value and the coal burst hazard level.

\begin{tabular}{lcc}
\hline Coal burst risk index & Risk level & VG anomaly $\left(\mathrm{km} / \mathrm{s}^{2}\right)$ \\
\hline 0 & None & $<0.05$ \\
1 & Weak & $0.05 \sim 0.15$ \\
2 & Moderate & $0.15 \sim 0.25$ \\
3 & Strong & $>0.25$ \\
\hline
\end{tabular}
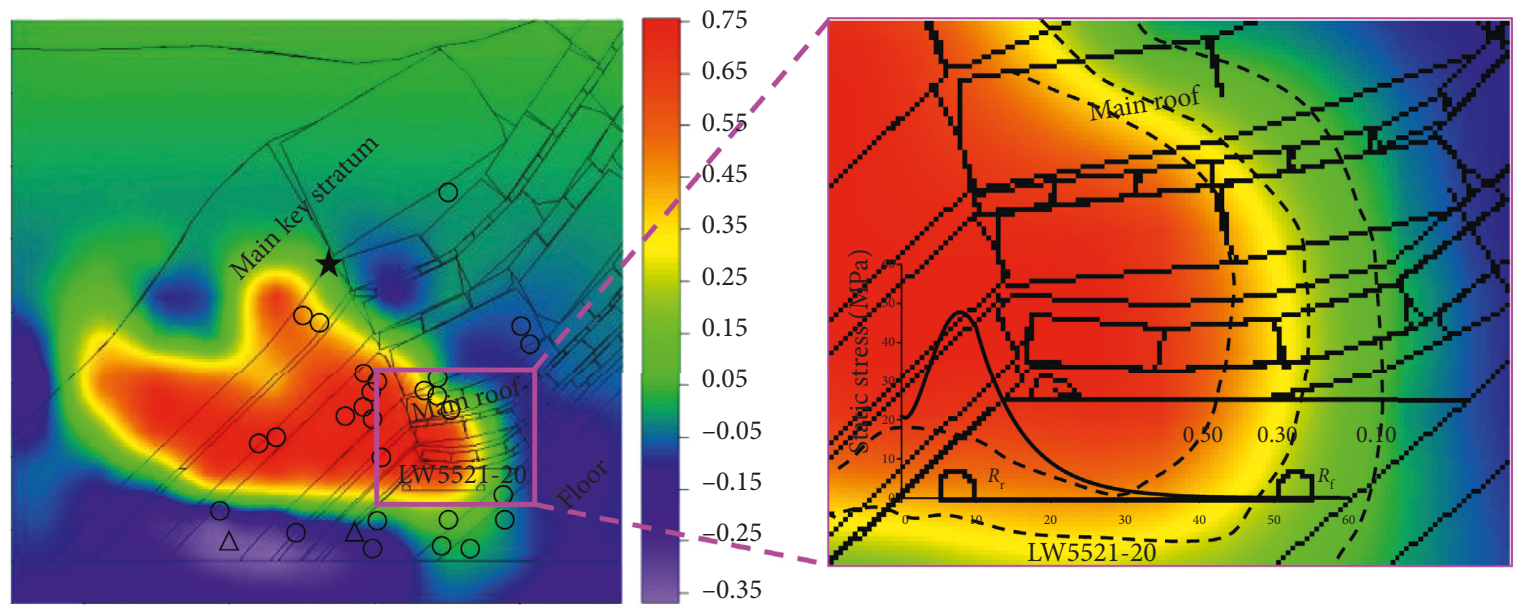

○ $1 E+3 \mathrm{~J} \sim 1 E+4 \mathrm{~J}$

$\triangle 1 E+4 \mathrm{~J} \sim 1 E+5 \mathrm{~J}$

$\star 1 E+5 \mathrm{~J} \sim 1 E+6 \mathrm{~J}$

(a)

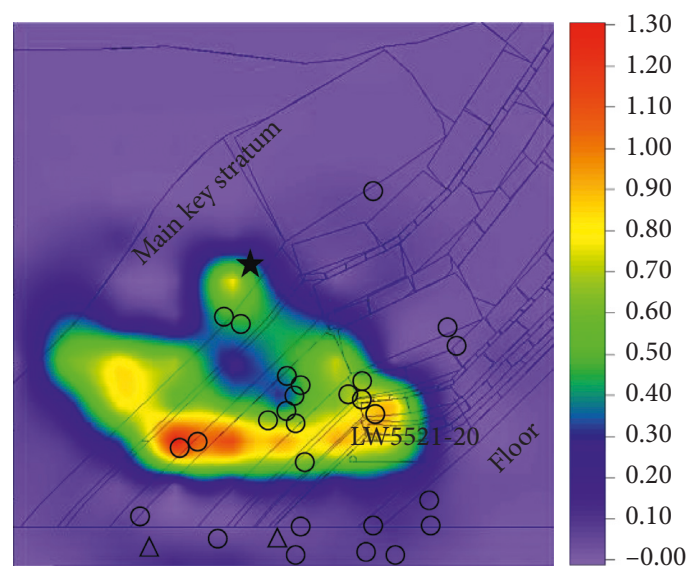

$\bigcirc 1 E+3 \mathrm{~J} \sim 1 E+4 \mathrm{~J}$
$\triangle 1 E+4 \mathrm{~J} \sim 1 E+5 \mathrm{~J}$
$\star 1 E+5 \mathrm{~J} \sim 1 E+6 \mathrm{~J}$

(b)

FIGURE 12: Tomography results and tremors with energies $E>10^{3} \mathrm{~J}$ between June 1, 2016, and June 30, 2016. (a) Seismic wave velocity anomaly distribution. (b) VG anomaly distribution.

4.4. Coal Burst Occurrence. On June 29, 2016, a coal burst with an energy release of $2.2 \times 105 \mathrm{~J}$ occurred in the $R_{\mathrm{r}}$ of the LW5521-20 panel at $49 \mathrm{~m}$ away from the open-off cut of the 2\# system and $35 \mathrm{~m}$ ahead of the mining position of the panel, as demonstrated in Figure 10(a). There were no geological structures, like faults and folds, around the location where the rock burst occurred. The section from $414 \mathrm{~m}$ to $430 \mathrm{~m}$ in the roof roadway showed heaving of $0.5 \mathrm{~m}$ due to the rock burst, and floor cracking of $10 \mathrm{~m}$ was found in the middle. The sides of the roof heaved $0.2 \sim 0.5 \mathrm{~m}$, and some anchor rods were broken. Moreover, the fracture was $0.6 \sim 0.8 \mathrm{~m}$ away from the borehole wall, as presented in Figure 13.

By combining theoretical analysis, superposed dynamic and static load test, and field monitoring data, the results of the three means are consistent and mutually verified. When mining the working face, hanging area of the thick and hard roof (main roof and main key strata) constantly rises, which 


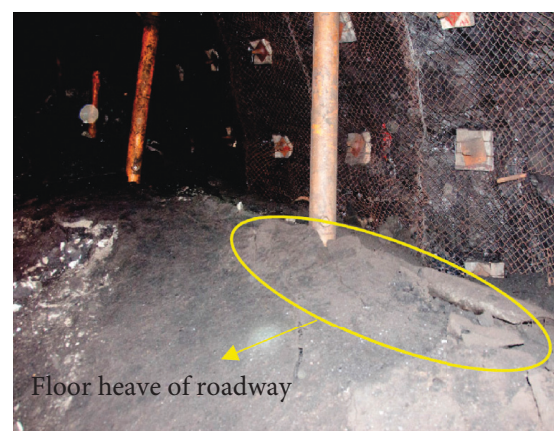

(a)

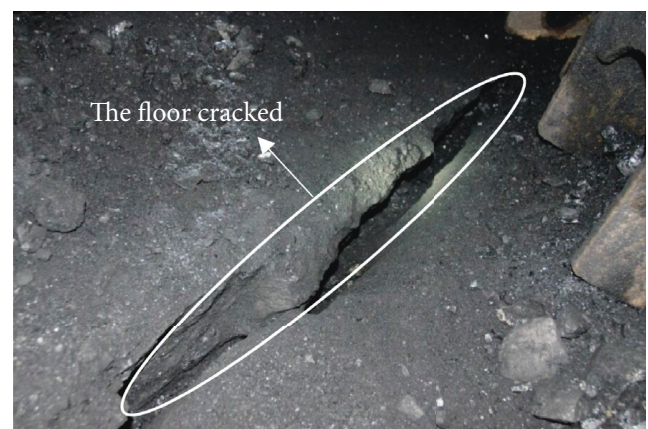

(b)

FIGURE 13: Coal burst in the roof roadway. (a) Floor heave of the roadway. (b) Cracking of the roadway floor.

aggravates the asymmetry of distribution of static stress on the $R_{\mathrm{r}}$ and $R_{\mathrm{f}}$ so that stress of the $R_{\mathrm{r}}$ is much larger than that of the $R_{\mathrm{f}}$. In the meanwhile, dynamic loads are produced by the breakage of the thick and hard roof and gradually attenuate in the transfer process, which further intensifies the hazard degree of the $R_{\mathrm{r}}$ after superposition of the dynamic loads with static stress. When stress reaches the limit borne by coal and rock in the $R_{\mathrm{r}}$, coal burst occurs.

\section{Conclusion}

(1) Based on characteristics of stress of the roof and floor in the SICS, the horizontal slice was divided into the triangular zone on the roof, the rectangular zone, and the triangular zone on the floor. The expression of stress distribution along the working face was deduced based on roof stress, and the stress distribution curve showed that static stress of coal mass in the $R_{\mathrm{r}}$ was obviously higher than that in the $R_{\mathrm{f}}$. Dynamic loads produced after breakage of the thick and hard roof attenuate with the increase of propagation distance and are then superposed with static stress after being transferred to the $R_{\mathrm{r}}$.

(2) In the superposed dynamic and static load test, distribution of AE events and areas with high wave velocity mainly concentrate on main key strata (the peak wave velocity is $4.52 \mathrm{~km} / \mathrm{s}$ ) and coal mass on the roof in lower slices (the peak wave velocity is $3.92 \mathrm{~km} / \mathrm{s}$ ). After mining the upper slices, stress of the $R_{\mathrm{r}}$ in lower slices rises, while that of the $R_{\mathrm{f}}$ decreases. When static stress is identical, peak acceleration rises with energy under dynamic loads and decreases with the rise of propagation distance of dynamic loads. Under high static stress, energy under dynamic loads required for coal burst of the roadway is smaller and dynamic and static stresses of the $R_{\mathrm{r}}$ are higher than those of the $R_{\mathrm{f}}$. Therefore, coal burst occurrence more likely appears in the $R_{\mathrm{r}}$.

(3) Field monitoring data reveal that MS events are mainly distributed on the roof side, as well as MS events with large energy $\left(>10^{4} \mathrm{~J}\right)$. According to tomographic results, wave velocity (the peak reaches 0.71 ) and anomaly gradient of wave velocity (the peak is 1.08) of shock waves before coal burst are also found in the $R_{\mathrm{r}}$. Therefore, the superposition of high static stress in the $R_{\mathrm{r}}$ and dynamic stress induced by roof breakage commonly results in coal burst occurrence in the $R_{\mathrm{r}}$, and the field analysis results are consistent with theoretical analysis and test results.

\section{Data Availability}

The in situ measurement data used to support the findings of this study are available from the corresponding author upon request.

\section{Conflicts of Interest}

The authors declare that there are no conflicts of interest regarding the publication of this paper.

\section{Acknowledgments}

Financial support for this work provided by the National Natural Science Foundation of China (Grant no. 51874292), the Natural Science Foundation of Jiangsu Province (Grant no. BK20180643), and the project funded by the Priority Academic Programme Development of Jiangsu Higher Education Institutions (no. SZBF2011-6-B35) is gratefully acknowledged.

\section{References}

[1] Y. P. Wu, K. Z. Liu, D. F. Yun, P. S. Xie, and H. W. Wang, "Research progress on the safe and efficient mining technology of steeply dipping seam," Journal of China Coal Society, vol. 39, no. 8, pp. 1611-1618, 2014.

[2] Y. Deng and S. Wang, "Feasibility analysis of gob-side entry retaining on a working face in a steep coal seam," International Journal of Mining Science and Technology, vol. 24, no. 4, pp. 499-503, 2014.

[3] M. Z. Gao, "Similarity model test of strata movement with steep seam," Chinese Journal of Rock Mechanics and Engineering, vol. 23, no. 3, pp. 441-445, 2004.

[4] Y. Zhang, B. Zhang, L. Li, S. Q. Zhang, J. K. Liu, and Z. Z. Zhao, "Study on the effect of roof fracture development on gas drainage in steep full-mechanized caving mining," 
Journal of Mining \& Safety Engineering, vol. 31, no. 5, pp. 809-813, 2014.

[5] C. Y. Liang, N. B. Wang, T. Qi, D. H. Jiang, and F. Cui, "Analysis on cause of deep coal and rock dynamic instability in steep inclined seam," Coal Science and Technology, vol. 40, no. 9, pp. 9-12, 2012.

[6] T. T. Du, K. Li, H. Lan, and X. D. Liu, "Rockburst process analysis in steeply-inclined extremely-thick coal seam," Journal of Mining \& Safety Engineering, vol. 35, no. 1, pp. 140-145, 2018.

[7] L. M. Dou and X. Q. He, "Electromagnetic emissions in rock and coal burst failures," Journal of Tsinghua University, vol. 41, no. 12 , pp. $86-88,2001$, in Chinese.

[8] L. M. Dou and X. Q. He, Theory and Technology of Rock Burst Prevention, China University of Mining and Press, Xuzhou, China, 2001, in Chinese.

[9] V. I. Frid, A. N. Shabarov, V. M. Proskuryakov, and V. A. Baranov, "Formation of electromagnetic radiation in coal stratum," Journal of Mining Science, vol. 28, no. 2, pp. 139-145, 1992.

[10] Y. Jiang, Y. Zhao, H. Wang, and J. Zhu, "A review of mechanism and prevention technologies of coal bumps in China," Journal of Rock Mechanics and Geotechnical Engineering, vol. 9, no. 1, pp. 180-194, 2017.

[11] Y. P. Wu, "Controlling pattern for dynamic stability of system "roof- support- floor"," Journal of China Coal Society, vol. 32, no. 4, pp. 341-346, 2007.

[12] Y. Z. Zhang and P. W. Shi, "Structural analysis of arch of spanning strata of top coal caving in steep seam," Chinese Journal of Rock Mechanics and Engineering, vol. 25, no. 1, pp. 79-82, 2006.

[13] X. P. Shao and P. W. Shi, "Solid simulation study of failure law of surrounding rock in mining steep seams," Journal of Mining \& Safety Engineering, vol. 23, no. 1, pp. 107-110, 2006.

[14] Y. P. Wu, P. S. Xie, and S. G. Ren, "Analysis of asymmetric structure around coal face of steeply dipping seam mining," Journal of China Coal Society, vol. 35, no. 2, pp. 182-184, 2010.

[15] W. Z. Li and W. J. Ju, "Fracture mechanical model of main roof along inclined for fully mechanized top coal caving in steep and extra thick coal seam," Journal of China Coal Society, vol. 33, no. 6, pp. 606-608, 2008.

[16] X. P. Lai, Y. P. Li, N. B. Wang, Y. H. Liu, and P. J. Yan, "Roof deformation characteristics with full-mechanized caving face based on beam structure in extremely inclined coal seam," Journal of Mining \& Safety Engineering, vol. 32, no. 6, pp. 871-876, 2015.

[17] X. P. Lai, H. Sun, P. F. Shan, C. L. Wang, N. Cui, and Y. R. Yang, "Acoustic emission and temperature variation in failure process of hard rock pillars sandwiched between thick coal seams of extremely steep," Chinese Journal of Rock Mechanics and Engineering, vol. 34, no. 11, pp. 2285-2292, 2015.

[18] Z. Y. Wang, L. M. Dou, and G. F. Wang, "Coal burst induced by horizontal section mining of a steeply inclined, extra-thick coal seam and its prevention: a case study from Yaojie No. 3 coal mine, China," Shock and Vibration, vol. 2019, Article ID 8469019, 13 pages, 2019.

[19] G. X. Xie, K. Yang, and Q. M. Liu, "Study on distribution laws of stress in inclined coal pillar for fully-mechanized top-coal caving face," Chinese Journal of Rock Mechanics and Engineering, vol. 25, no. 3, pp. 545-549, 2006.

[20] J. He, Research of Mining Dynamic Loading Effect and its Induced Rock Burst in Coal Mine, China University of Mining and Technology, Xuzhou, China, 2013.
[21] A. G. Thompson, E. Villaescusa, and C. R. Windsor, "Ground support terminology and classification, an update," Geotechnical and Geological Engineering, vol. 30, no. 3, pp. 553$580,2012$.

[22] J. Hadjigeorgiou and Y. Potvin, "A critical assessment of dynamic rock reinforcement and support testing facilities," Rock Mechanics and Rock Engineering, vol. 44, no. 5, pp. 565-578, 2011.

[23] G. Y. Wang, Technic Study on Enhancing the Explosion Resisting Capacity of Underground Opening Reinforced, University of Science and Technology of China, Hefei, China, 2009.

[24] M. He, X. Jia, W. Gong, and L. Faramarzi, "Physical modeling of an underground roadway excavation vertically stratified rock using infrared thermography," International Journal of Rock Mechanics and Mining Sciences, vol. 47, no. 7, pp. 1212-1221, 2010.

[25] M. A. Meguid, O. Saada, M. A. Nunes, and J. Mattar, "Physical modeling of tunnels in soft ground, a review," Tunnelling and Underground Space Technology, vol. 23, no. 2, pp. 185-198, 2008.

[26] H. Z. Xing, Q. B. Zhang, C. H. Braithwaite, B. Pan, and J. Zhao, "High-speed photography and digital optical measurement techniques for geomaterials: fundamentals and applications," Rock Mechanics and Rock Engineering, vol. 50, no. 6, pp. 1611-1659, 2017.

[27] C. H. Scholz, "The frequency-magnitude relation of microfracturing in rock and its relation to earthquakes," BSSASeismological Society of America, vol. 58, no. 1, pp. 399-415, 1968.

[28] X. Li, Z. Zhou, T.-S. Lok, L. Hong, and T. Yin, "Innovative testing technique of rock subjected to coupled static and dynamic loads," International Journal of Rock Mechanics and Mining Sciences, vol. 45, no. 5, pp. 739-748, 2008.

[29] L. M. Dou, W. Cai, S. Y. Gong, R. J. Han, and J. Liu, "Dynamic risk assessment of rock burst based on the technology of seismic computed tomography detection," Journal of China Coal Society, vol. 39, no. 2, pp. 238-244, 2014.

[30] A. Y. Cao, C. B. Wang, G. C. Jing, W. Cai, G. A. Zhu, and J. Li, "Passive velocity tomography for mudstone under uniaxial compression using acoustic emission," Geosciences Journal, vol. 21, no. 1, pp. 93-109, 2017.

[31] S. Y. Gong, L. M. Dou, X. J. Xu, J. He, C. P. Lu, and H. He, "Experimental study on the correlation between stress and P-wave velocity for burst tendency coal-rock samples," Journal of Mining \& Safety Engineering, vol. 29, no. 1, pp. 67-71, 2012.

[32] W. Cai, L. Dou, A. Cao, S. Gong, and Z. Li, "Application of seismic velocity tomography in underground coal mines: a case study of Yima mining area, Henan, China," Journal of Applied Geophysics, vol. 109, pp. 140-149, 2014.

[33] Z. Mu, G. Liu, J. Yang et al., "Theoretical and numerical investigations of floor dynamic rupture: a case study in Zhaolou Coal Mine, China," Safety Science, vol. 114, pp. 1-11, 2019. 


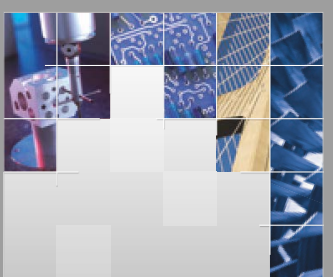

\section{Enfincering}
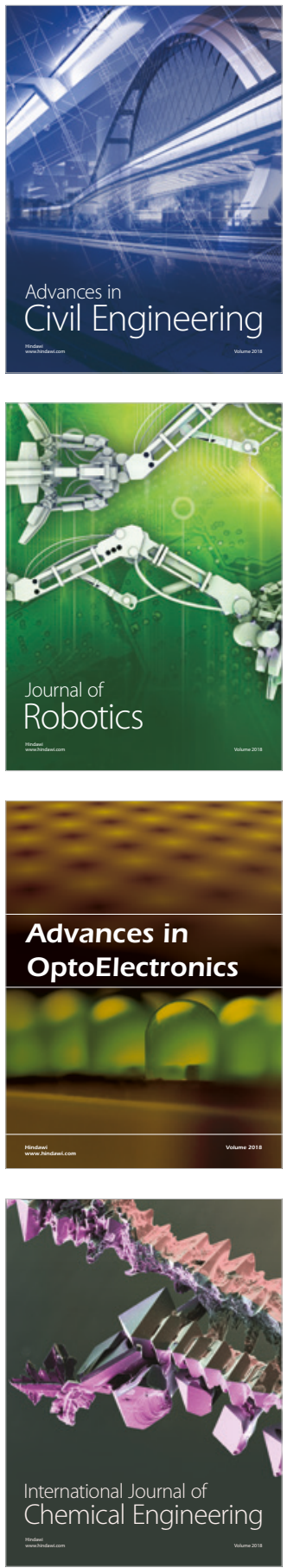

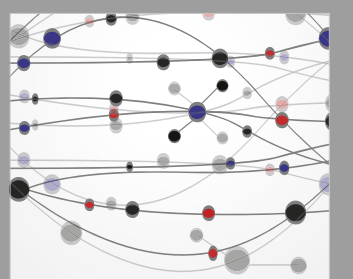

\section{Rotating \\ Machinery}

The Scientific World Journal

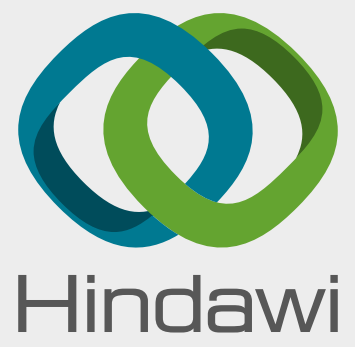

Submit your manuscripts at

www.hindawi.com
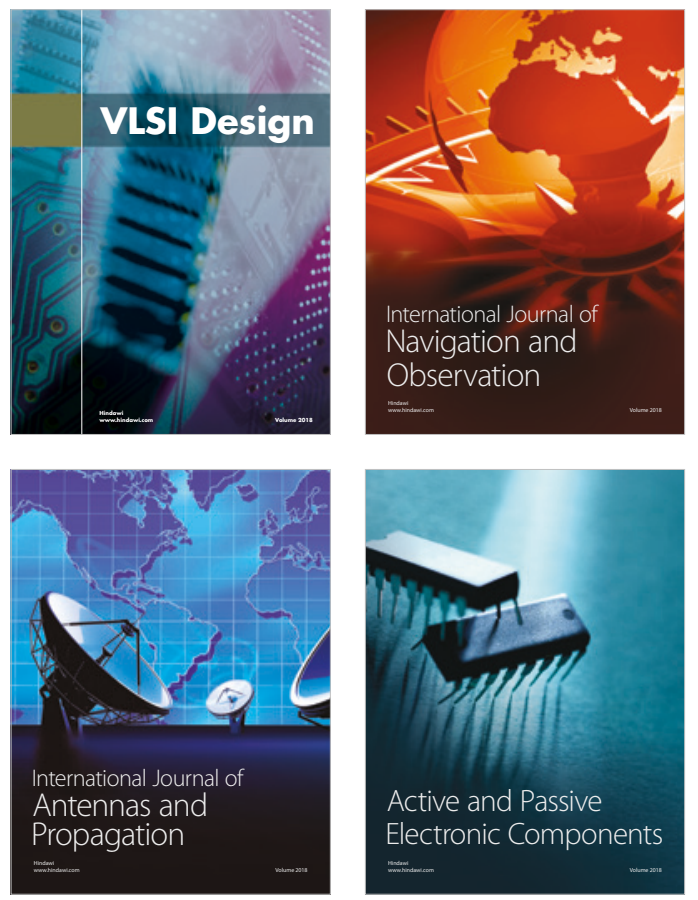
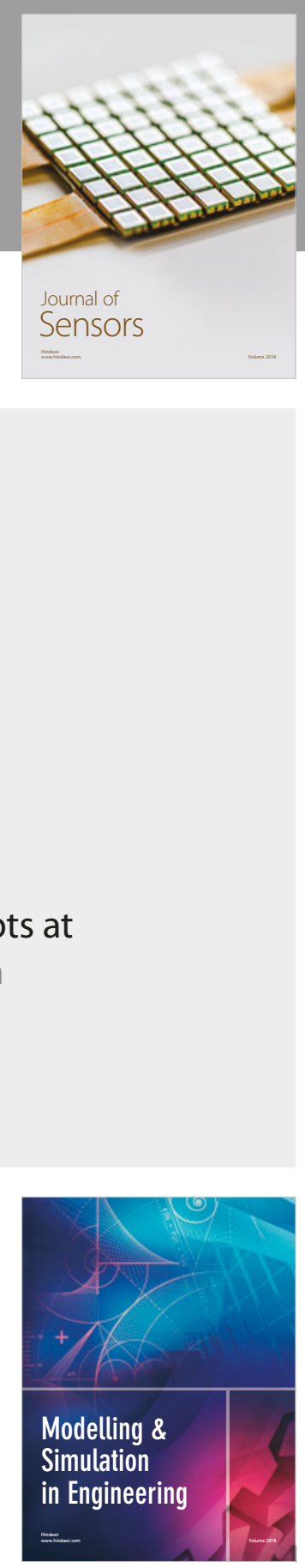

\section{Advances \\ Multimedia}
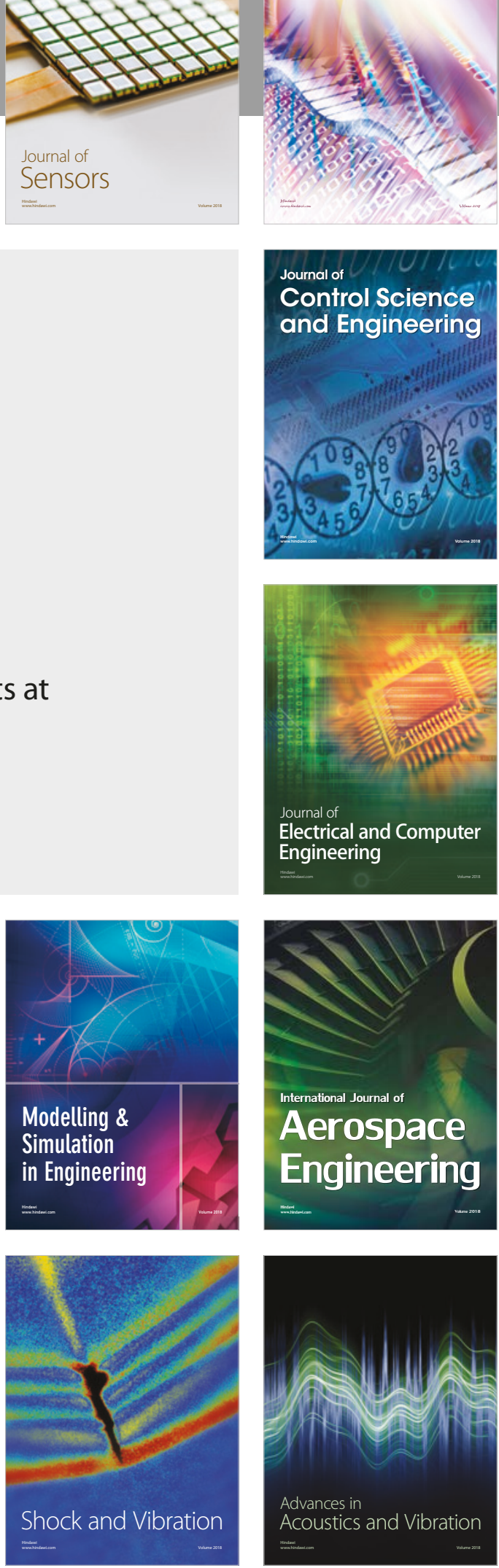